\title{
eIF6 rebinding dynamically couples ribosome maturation and translation
}

Pekka Jaako ${ }^{1,2,3 \#}$, Alexandre Faille ${ }^{1,2,3}$, Shengjiang Tan ${ }^{1,2,3}$, Chi C. Wong ${ }^{1,5}$ Norberto Escudero-Urquijo ${ }^{1,2,3}$, Pablo Castro-Hartmann ${ }^{1,2,3}$, Penny Wright $^{4}$, Christine Hilcenko ${ }^{1,2,3}$, David J. Adams ${ }^{5}$, Alan J. Warren ${ }^{1,2,3^{*}}$.

${ }^{1}$ Department of Haematology, University of Cambridge, Hills Road, Cambridge, CB2 OXY, UK

${ }^{2}$ Cambridge Institute for Medical Research, Keith Peters Building, Hills Road, Cambridge, CB2 0XY

${ }^{3}$ Wellcome Trust-Medical Research Council Stem Cell Institute, University of Cambridge, Cambridge, UK

${ }^{4}$ Department of Pathology, Cambridge University Hospitals, Hills Road, Cambridge CB2 0QQ, UK

${ }^{5}$ Experimental Cancer Genetics, Wellcome Trust Sanger Institute, Cambridge, United Kingdom

${ }^{\#}$ Current address: Sahlgrenska Center for Cancer Research, Department of Microbiology and Immunology, University of Gothenburg, 41390 Gothenburg, Sweden.

*Correspondence: ajw1000@cam.ac.uk

Running title: eIF6 links ribosome maturation and recycling

Keywords: ribosome recycling, eIF6, SBDS, EFL1, ribosomopathy, translation, ribosome, Shwachman-Diamond syndrome 


\begin{abstract}
Protein synthesis is a cyclical process consisting of translation initiation, elongation, termination and ribosome recycling. The release factors SBDS and EFL1 (both mutated in the leukaemia predisposition disorder Shwachman-Diamond syndrome) license entry of nascent $60 \mathrm{~S}$ ribosomal subunits into active translation by evicting the anti-association factor eIF6 from the 60S intersubunit face. Here, we show that in mammalian cells, eIF6 holds all free cytoplasmic 60S subunits in a translationally inactive state and that SBDS and EFL1 are the minimal components required to recycle these 60 S subunits back into additional rounds of translation by evicting eIF6. Increasing the dose of eIF6 in mice in vivo impairs terminal erythropoiesis by sequestering post-termination $60 \mathrm{~S}$ subunits in the cytoplasm, disrupting subunit joining and attenuating global protein synthesis. Our data reveal that ribosome maturation and recycling are dynamically coupled by a mechanism that is disrupted in an inherited leukaemia predisposition disorder.
\end{abstract}




\section{INTRODUCTION}

Every minute, a growing HeLa cell synthesises around 7500 ribosomal subunits which decode messenger RNA to make protein through the four successive steps of translation: initiation, elongation, termination and recycling. Removal of the highly conserved nucleolar shuttling factor eukaryotic initiation factor 6 (eIF6) from the intersubunit face of the nascent large 60S ribosomal subunit is essential to license its entry into translation ${ }^{1}$, because eIF6 sterically inhibits the large $60 \mathrm{~S}$ ribosomal subunit from joining to the small $40 \mathrm{~S}$ subunit to form an actively translating ribosome $e^{2,3}$. eIF6 is initially recruited to pre-60S ribosomal subunits in the nucleolus ${ }^{4}$. Following export of the pre-60S particles to the cytoplasm, the GTPase EFL1 (elongation factor-like 1) and its cofactor SBDS (Shwachman-Bodian-Diamond syndrome) evict eIF6 during the final step in maturation of the nascent $60 \mathrm{~S}$ subunit ${ }^{5-}$ 11

Disruptive variants in both $\operatorname{SBDS}^{12}$ and $\mathrm{EFL1}^{13}$ cause the inherited leukaemia predisposition disorder Shwachman-Diamond syndrome (SDS) ${ }^{14}$. Missense variants in eIF6 can bypass the fitness defect of yeast cells lacking the SBDS orthologue Sdo1 by reducing eIF6 binding to the $60 \mathrm{~S}$ subunit ${ }^{7}$. In addition, diverse somatic genetic events including point mutations, interstitial deletion and reciprocal chromosomal translocation rescue the germline ribosome defect in SBDS-deficient haematopoietic cells either by reducing eIF6 expression or by disrupting the interaction of eIF6 with the $60 \mathrm{~S}$ subunit ${ }^{15,16}$. The observation that mutations in eIF6 can rescue the defects in ribosomal subunit joining and translation initiation observed in SBDS-deficient cells ${ }^{15}$ raises the possibility that SBDS and EFL1 may have a more general role in translation beyond their function in nascent $60 \mathrm{~S}$ subunit maturation. Cryo-electron microscopy (cryo-EM) studies further support this hypothesis by 
revealing that eIF6 is bound to $60 \mathrm{~S}$ ribosome quality control intermediates ${ }^{17,18}$, suggesting that there are some contexts in which eIF6 may rebind to mature $60 \mathrm{~S}$ ribosomal subunits in vivo.

In eukaryotes, translation termination begins with the recognition of a stop codon in the A site of the 80S ribosome by the release factors eRF1 and GTP-bound eRF $3^{19}$. Peptide release is temporally coupled to splitting of the $80 \mathrm{~S}$ ribosome into a free $60 \mathrm{~S}$ and a $40 \mathrm{~S}$ subunit bound to deacylated tRNA and mRNA by the essential ATP-binding cassette protein Rli1 (yeast)/ABCE1 (mammals) ${ }^{20,21}$. The deacylated tRNA is subsequently removed, promoting dissociation of the $40 \mathrm{~S}$ subunit from the mRNA $^{20,22}$. ABCE1 blocks $40 \mathrm{~S}$ rebinding to the $60 \mathrm{~S}$ subunit by sterically hindering the formation of an intersubunit bridge between the $60 \mathrm{~S}$ protein $\mathrm{uL} 14$ and the $40 \mathrm{~S}$ rRNA helix $h 44^{23}$. However, the possibility that eIF6 rebinding might similarly sequester post-termination recycled $60 \mathrm{~S}$ subunits in a translationally inactive state has not been addressed. Dissociated 40S and 60S subunits may immediately re-engage in further rounds of translation initiation or alternatively, in conditions of stress, enter a reservoir of translationally inactive $80 \mathrm{~S}$ ribosomes ${ }^{24-27}$, that can again be recycled in an $\mathrm{ABCE} 1-\mathrm{dependent}$ manner ${ }^{28}$. Interestingly, ribosome recycling becomes critical for ribosome homeostasis during erythroid differentiation, as the natural loss of ABCE1 limits ribosome availability and results in the accumulation of posttermination, unrecycled ribosomes in the $3^{\prime}$ UTRs of mRNAs ${ }^{29}$.

Here, we test the hypothesis SBDS and EFL1 act as general eIF6 release factors to regulate post-termination $60 \mathrm{~S}$ ribosomal subunit recycling. Using cryo-EM, we show that eIF6 binds to the majority of free cytoplasmic $60 \mathrm{~S}$ subunits in mammals, thereby holding them in a translationally inactive state. We reveal that SBDS and EFL1 are the minimal components required to evict 60S-rebound eIF6 and 
recycle post-termination $60 \mathrm{~S}$ subunits back into the actively translating pool. Consistent with the requirement for efficient ribosome recycling during erythropoiesis, graded overexpression of eIF6 in mice perturbs late steps in erythroid differentiation by sequestering free $60 \mathrm{~S}$ subunits, blocking subunit joining and attenuating global translation. Our data support a wider role for SBDS and EFL1 as translational regulators that dynamically couple $60 \mathrm{~S}$ subunit maturation with ribosome recycling through the release of rebound eIF6.

\section{RESULTS}

eIF6 holds free cytoplasmic 60S subunits in a translationally inactive state in vivo

We set out to test the hypothesis that eIF6 maintains free cytoplasmic $60 \mathrm{~S}$ subunits in a translationally inactive state in primary haematopoietic cells in vivo. Immunoblotting of cell extracts purified from primary murine c-kit + bone marrow cells revealed that around $14 \%$ of the eIF6 protein co-migrated with free $60 \mathrm{~S}$ ribosomal subunits, while the majority was distributed in the free fraction (Figure 1A). Single particle cryo-electron microscopy (cryo-EM) analysis of free $60 \mathrm{~S}$ particles purified from primary murine c-kit+ bone marrow cells revealed that eIF6 is stably bound to the intersubunit face of at least $83 \%$ of cytoplasmic mature $60 \mathrm{~S}$ subunits (Figure 1B).

At an overall resolution of $3.1 \AA$, our cryo-EM reconstructions allowed us to build and refine atomic models of murine eIF6 bound to the $60 \mathrm{~S}$ ribosomal subunit (Figure 1C and Supplementary Figure 1). Conserved from prokaryotes to human, eIF6 is a member of the pentein protein superfamily with five-fold pseudosymmetry ${ }^{30}$. Consistent with previous structures from yeast ${ }^{3}$, Tetrahymena $^{31}$ and human cells ${ }^{15}$, murine eIF6 sterically inhibits $40 \mathrm{~S}$ ribosomal subunit joining by binding to a 
conserved site on the intersubunit face of the $60 \mathrm{~S}$ subunit involving the $\mathrm{C}$ terminus of $\mathrm{uL14}{ }^{32}$, the sarcin-ricin loop (SRL), uL3 (residues 58-71) and the N terminus of eL24 (Figure 1D). We conclude that in primary murine haematopoietic cells, eIF6 holds all free $60 \mathrm{~S}$ ribosomal subunits in a translationally inactive state by binding to the $60 \mathrm{~S}$ intersubunit face. These data support the hypothesis that eIF6 must be released from the $60 \mathrm{~S}$ ribosomal subunit to allow $80 \mathrm{~S}$ ribosome assembly ${ }^{1}$. However, we were unable to discriminate nascent 60S-eIF6 complexes versus eIF6 rebound to mature 60S subunits.

\section{Endogenous eIF6 can rebind mature cytoplasmic 60S subunits}

The ribosome quality control (RQC) pathway recognises and rescues stalled translation complexes. Following ribosome dissociation, components of the RQC complex remain bound to the $60 \mathrm{~S}$ subunit together with eIF $6^{17,33}$. Taken together with the finding that eIF6 is bound to virtually all mature cytoplasmic 60S ribosomal subunits, we hypothesised that during canonical translation termination (and RQC), eIF6 might rebind to mature 60S particles and require dynamic recycling by SBDS and the GTPase EFL1.

To support this hypothesis, we first tested the ability of eIF6 to rebind mature 60S particles that had been dissociated from $80 \mathrm{~S}$ couples. Using immunoblotting, we examined the distribution of endogenous eIF6 following sucrose gradient fractionation of cell extracts prepared from c-kit+ murine bone marrow cells in $80 \mathrm{~S}$ dissociating (2 $\mathrm{mM} \mathrm{Mg}, 500 \mathrm{mM} \mathrm{KCl})$ conditions. In contrast to non-dissociating conditions where eIF6 predominantly migrates in the free fraction (Figure 1A), eIF6 comigrated almost entirely with the 60S subunit (Figure 2A). Consistent with 
previous work ${ }^{1}$, we conclude that endogenous eIF6 can rebind mature cytoplasmic 60S subunits in mammalian cells.

\section{SBDS and EFL1 are sufficient to release eIF6 rebound to $60 \mathrm{~S}$ subunits}

We next examined whether human SBDS, EFL1 and GTP are sufficient to promote the release of eIF6 rebound to mature cytoplasmic 60S subunits. We biochemically reconstituted an ex vivo assay that coupled eIF6 release from 60S subunits to their reassembly into $80 \mathrm{~S}$ ribosomes by adding recombinant human SBDS and EFL1 to eIF6-loaded 60S subunits isolated from c-kit+ bone marrow cells. A schematic overview of the assay is shown in Figure 2B. As shown in the representative experiment in Figure 2C, compared with GTP alone (left panel), the addition of SBDS, EFL1 and GTP (right panel) to eIF6-loaded 60S subunits promoted redistribution of eIF6 into the free fraction of the sucrose gradient as detected by immunoblotting, with a concomitant 1.8 -fold increase in $80 \mathrm{~S}$ ribosome reassembly. We conclude that in the presence of GTP, SBDS and EFL1 are sufficient to release eIF6 that has rebound to mature $60 \mathrm{~S}$ particles. These data provide biochemical support for the hypothesis that SBDS and EFL1 function as general release factors with dual roles in nascent $60 \mathrm{~S}$ subunit maturation and in ribosome recycling.

\section{Genetic interactions between SBDS, EFL1 and eIF6}

We reasoned that if eIF6 dynamically rebinds to post-termination $60 \mathrm{~S}$ ribosomal subunits, increasing the dose of eIF6 in vivo would titrate out free $60 \mathrm{~S}$ subunits to impair ribosomal subunit joining, reduce global protein synthesis and induce growth defect. Consistent with this hypothesis, ubiquitous overexpression of wild type eIF6 (but not eIF6 missense mutants identified in SDS haematopoietic cells that map to the 
interface with the $60 \mathrm{~S}$ subunit) induces late larval lethality in Drosophila ${ }^{15}$. Furthermore, overexpression of SDS patient-derived eIF6 missense mutations can fully rescue the lethality of Sbds-deficient flies ${ }^{15}$.

To further test the in vivo genetic interactions between Sbds and eIF6, we depleted $S b d s$ using $\mathrm{RNAi}^{15}$, allowing flies to develop to adult stage albeit more slowly compared with wild type controls (Figure 3A). At $29{ }^{\circ} \mathrm{C}, 5.4 \%$ of $S b d s$ depleted flies develop from pupae to adults $(n=269,3$ replicates $)$; at $25{ }^{\circ} \mathrm{C}, 55.5 \%$ of pupae develop to adults $(\mathrm{n}=276,2$ replicates). RNAi-mediated depletion of $S b d s$ enhanced the growth defect induced by ubiquitous overexpression of eIF6, causing lethality at the early larval stage (Figure 3A). In the developing ommatidia, selective eIF6 overexpression induced a small, rough eye phenotype (Supplementary Figure 2) that was enhanced either by doubling the dose of eIF6 or by depleting Sbds or Efll by RNAi (Figure 3B, Supplementary Figure 2). Selective overexpression of eIF6 in the Drosophila wing disc reduced global protein synthesis as measured by Opropargyl-puromycin (OP-puro) incorporation (Figure 3C). These genetic data support the hypothesis that SBDS and EFL1 function in mobilizing eIF6 that has rebound to cytoplasmic 60S ribosomal subunits in vivo.

\section{eIF6 dose-dependent inhibition of ribosomal subunit joining in vivo}

We set out to further validate the hypothesis that eIF6 dynamically rebinds to post-termination cytoplasmic $60 \mathrm{~S}$ ribosomal subunits by engineering a transgenic eIF6 mouse strain that permits doxycycline (Dox, tetracycline analogue)-inducible and graded overexpression of the human EIF6 transgene by constitutively expressing the M2-reverse tetracycline transactivator (M2-rtTA) at the Rosa26 promoter ${ }^{34}$ (Figures 4A, 4B). M2-rtTA is a mutant of rtTA that has increased stability, reduced 
background expression and improved inducibility in the presence of Dox ${ }^{35}$. This transgenic mouse strain exhibits widespread constitutive expression of M2-rtTA, allowing for Dox-inducible transactivation of the human EIF6 cDNA. We adjusted the level of eIF6 overexpression by breeding animals that were heterozygous or homozygous for the M2-rtTA at the Rosa26 locus and carried one or two copies of the human EIF6 transgene at the Collal locus (Figure 4B). To evaluate the level of EIF6 transgene expression, we treated cultured c-Kit+ bone marrow cells with Dox and performed quantitative real-time PCR to measure EIF6 mRNA. We designed two sets of primers to distinguish endogenous mouse Eif6 mRNA from total (endogenous + transgene) EIF6 mRNA to verify the transgene copy number-dependent increase in total EIF6 expression (Figure 4C). The increase in EIF6 mRNA led to a significant increase in the level of eIF6 protein expression compared with control animals (Figure 4D).

Next, we assessed the impact of increasing doses of eIF6 on ribosome assembly in vivo by fractionating cell extracts in the presence of cycloheximide from Dox-treated c-Kit + bone marrow cells by sucrose gradient sedimentation. Depending on the level of overexpression, the increased dose of eIF6 promoted a reduction in the 80S:60S ratio, consistent with a subunit-joining defect (Figure 4E). Parallel experiments using high salt buffer to specifically dissociate inactive mRNA-free $80 \mathrm{~S}$ monosomes $^{36}$, further highlighted the eIF6 dose-dependent reduction in actively translating $80 \mathrm{~S}$ ribosomes (Figure 4F). Finally, by using a magnesium-free buffer system, we observed that the ratio of $60 \mathrm{~S}$ to $40 \mathrm{~S}$ subunits was preserved with an intermediate dose of eIF6 (Figure 4G). Although higher eIF6 overexpression resulted in a relative decrease in $60 \mathrm{~S}$ subunits (Figure $\mathbf{4 H}$ ), this is likely to be a secondary consequence of the profound reduction in global protein synthesis. We conclude that 
graded eIF6 overexpression induces a dose-dependent ribosomal subunit joining defect in vivo. Importantly, the observed ribosomal subunit joining defect upon eIF6 overexpression closely mimics the subunit joining defect caused by eIF6 retention on the 60S subunit that is observed in $S b d s$ - or Efll deficient mice or patient-derived lymphoblasts $8,9,13,37$. Taken together with our genetic data in Drosophila, we propose that the most logical interpretation of these findings is that eIF6 rebinds to posttermination recycling $60 \mathrm{~S}$ subunits from which it is dynamically recycled by SBDS and EFL1. These data support the hypothesis that SBDS and EFL1 translationally activate nascent 60 S subunits and in addition act as general eIF6 release factors that dynamically recycle eIF6-bound post-termination 60S subunits back into additional rounds of translation.

\section{Terminal erythroid differentiation is sensitive to eIF6 dosage}

We reasoned that during mammalian haematopoiesis, the erythroid lineage might be particularly sensitive to an increased dose of eIF6 and aberrant ribosome homeostasis due to the increased dependence of terminal erythroid differentiation on ribosome recycling as a consequence of natural loss of the ribosome recycling factor $\mathrm{ABCE}^{29}$. To test this hypothesis, we induced eIF6 overexpression in vivo in transgenic mice.

Detailed analysis of mice carrying two copies of the M2-rtTA transgene and either one or two copies of the EIF6 transgene was precluded because of the rapid weight loss induced in these animals. By contrast, mice that were heterozygous for both transgenes $\left(M 2-r t T A /+\right.$; EIF6/+, herein called eIF6 ${ }^{\text {hi }}$ mice) did not lose weight acutely in response to Dox administration (Supplementary Figure 3). We therefore restricted our analysis to eIF $6^{\text {hi }}$ mice. 
Immature (lineage-, Sca-1+, c-Kit+; LSK), myeloid (preGM/GMP) and erythroid (preCFU-E/CFU-E) haematopoietic progenitor cells isolated from Doxtreated eIF6 ${ }^{\text {hi }}$ mice showed a 2-4 fold increase in EIF6 mRNA (Supplementary Figure 4A), while sucrose gradient sedimentation analysis of extracts from cultured c-Kit+ bone marrow cells showed accumulation of free $40 \mathrm{~S}$ and $60 \mathrm{~S}$ subunits compared with control (Supplementary Figure 4B). Immunoblotting revealed a robust increase in eIF6 protein across the gradient (Supplementary Figure 4C). Compared with controls, the overexpressed eIF6 protein predominantly accumulated in the cytoplasm of freshly isolated bone marrow cells in eIF6 ${ }^{\text {hi }}$ mice (Supplementary Figure 4D).

After two weeks of Dox administration, eIF6 ${ }^{\text {hi }}$ mice developed persistent macrocytic anaemia with a significant reduction in the reticulocyte count compared with controls (Figure 5A and 5B). While the platelet count increased, the total white blood cell count was unaffected (Supplementary Figure 5). Histological examination of the bone marrow revealed erythroid hyperplasia in eIF $6^{\text {hi }}$ mice, with an increased frequency of erythroid precursors compared with controls (Supplementary Figure 6A). In addition, the spleen was enlarged in eIF6 ${ }^{\text {hi }}$ mice (Supplementary Figure 6B), due to marked expansion of erythroid precursors (Supplementary Figure 6C).

To further characterise haematopoiesis in the eIF $6^{\text {hi }}$ mice, we analysed bone marrow cells by flow cytometry ${ }^{38,39}$, using the gating strategy shown schematically in Supplementary Figure 7. The eIF6 ${ }^{\text {hi }}$ mice showed no significant differences in overall bone marrow cellularity relative to controls (Supplementary Figure 8A). Although the frequency of myeloid and multipotent progenitors (preGM and MPPs) decreased, the frequency of erythroid progenitors (preCFU-E and CFU-E) (Supplementary Figure 8B) and precursor cells (Figure 5C-E) was significantly 
increased. A similar increase in the frequency of erythroid precursors was detected by flow cytometry in the spleen (Supplementary Figure 8C). Within the bone marrow, we identified an abnormal population of orthochromatic erythroblast-like cells $\left(\mathrm{CD} 44^{\mathrm{lo}} \mathrm{FSC}^{\mathrm{lo}}\right)$ containing a highly condensed nucleus and low cytoplasmic volume (Figure 5C-E).

We hypothesised that an increased dose of eIF6 might impair erythroblast enucleation during the terminal steps of erythroid differentiation, promoting the accumulation of orthochromatic erythroblast-like cells, but reducing the numbers of reticulocytes. To test this, we applied Amnis ImageStream technology ${ }^{40,41}$ to visualise active nuclear extrusion by bone marrow erythroblasts, dividing the process into early, intermediate and late stages (Figure 5F and Supplementary Figure 9). Compared with controls, in Dox-treated eIF6 ${ }^{\text {hi }}$ mice we classified more erythroblasts in the early or intermediate stages of enucleation compared with late steps (Figure 5G). We conclude that an increased dose of eIF6 impairs terminal enucleation of orthochromatic erythroblasts in vivo.

We next set out to determine whether the eIF6-dependent erythroid differentiation defect was intrinsic to eIF6 ${ }^{\text {hi }}$ haematopoietic cells. Consistent with this hypothesis, ex vivo differentiation of CFU-Es/proerythroblasts isolated from Doxtreated eIF $6^{\text {hi }}$ mice recapitulated the eIF6-dependent defect in terminal erythropoiesis (Supplementary Figure 8D). Furthermore, non-competitive transplantation of bone marrow cells from eIF $6^{\text {hi }}$ mice into lethally irradiated wild type congenic recipients also recapitulated the eIF6 dose-dependent haematopoietic abnormalities (Supplementary Figure 10). Taken together, our data indicate that the terminal erythroid maturation defects are intrinsic to eIF $6^{\text {hi }}$ haematopoietic cells. 


\section{Attenuated protein synthesis impairs terminal erythroblast enucleation}

We hypothesised that increasing the dose of eIF6 would alter ribosome homeostasis during erythropoiesis by shifting the equilibrium towards ribosomal subunit dissociation, thereby attenuating protein synthesis. To test this, we quantified the rate of global protein synthesis in erythroid cells in vivo by measuring OP-puro incorporation. Indeed, compared with controls, we observed a significant decrease in OP-puro incorporation in late poly- and orthochromatic erythroid precursors from Dox-treated eIF6 ${ }^{\text {hi }}$ mice (Figure 6A). These data demonstrate that eIF6 overexpression impairs terminal erythroid differentiation by a mechanism that directly or indirectly attenuates protein synthesis.

We reasoned that the reduced rate of protein synthesis in late erythroblasts from Dox-treated eIF6 ${ }^{\text {hi }}$ mice likely reflects altered ribosome homeostasis as a consequence of an increase in the relative ratio of eIF6 to ribosomes during terminal erythroid differentiation. To test this hypothesis, we sorted identical numbers of erythroid progenitor and precursor cells from Dox-treated mice and performed immunoblotting to visualise eIF6 and Rps19 (as a marker for cellular ribosome levels). In control mice, the levels of eIF6 and Rps19 peaked in early erythroblasts and progressively declined during terminal erythroid differentiation (Figure 6B). By contrast, erythroblasts in Dox-induced eIF6 ${ }^{\text {hi }}$ mice exhibited sustained high levels of eIF6 (Figure 6B). The relative intensity of thiazole orange staining (correlating with cellular ribosomal RNA content) of freshly isolated erythroblasts was consistent with a progressive decline in cellular ribosome levels during terminal erythroid maturation (Figure 6C). Taken together, these results indicate that an increased dose of eIF6 relative to ribosomal subunits is sustained in the $\mathrm{eIF}^{\mathrm{hi}}$ mice throughout erythropoiesis. Erythroid differentiation is likely susceptible to increased eIF6 dosage 
due to the combined shutdown in new ribosome synthesis in early erythroblasts ${ }^{42}$ together with the loss of effective ribosome recycling through natural loss of the ribosome recycling factor $\mathrm{ABCE} 1$ during terminal differentiation ${ }^{29}$. We propose that the increased dose of eIF6 titrates out recycled post-termination $60 \mathrm{~S}$ subunits during late erythroid differentiation to push the equilibrium in favour of ribosomal subunit dissociation, impaired translation initiation and attenuated protein synthesis. Finally, consistent with the impact of eIF6 overexpression on terminal erythroid differentiation, inhibition of protein synthesis with the translational elongation inhibitor homoharringtonine in prospectively isolated wild-type orthochromatic erythroblasts recapitulated the erythroblast enucleation defect observed in eIF $6^{\text {hi }}$ mice

\section{(Figure 6D).}

\section{DISCUSSION}

In this study, we have identified a critical role in the regulation of translation initiation for the SBDS and EFL1 proteins through their role as general eIF6 release factors. Using cryo-EM, we provide direct evidence that eIF6 holds virtually all free cytoplasmic $60 \mathrm{~S}$ subunits in mammalian cells in a translationally inactive state and show that SBDS and EFL1 are the minimal components required to recycle eIF6 that has rebound to post-termination 60S subunits. Depletion of Sbds or Efl1 exacerbates the growth defects caused by eIF6 overexpression in Drosophila in vivo, while eIF6 overexpression in mice causes a dose-dependent defect in ribosomal subunit joining by rebinding and titrating out post-termination $60 \mathrm{~S}$ subunits from active translation. The observation that inactive $80 \mathrm{~S}$ monosomes accumulate in eIF6 haploinsufficient mice $^{43}$ also supports the hypothesis that eIF6 prevents the formation of inactive $80 \mathrm{~S}$ monosomes by binding to post-termination $60 \mathrm{~S}$ subunits. Taken together, our data 
support a role for SBDS and EFL1 in regulating ribosome homeostasis by coupling the final step in cytoplasmic $60 \mathrm{~S}$ subunit maturation with post-termination $60 \mathrm{~S}$ ribosomal subunit recycling through their role as general eIF6 release factors (Figure 7).

Translation of mRNA occurs in four steps: initiation, elongation, termination and ribosome recycling. During the normal translation cycle, once the ribosome reaches the stop codon of the mRNA, eRF1 and eRF3 recognise the stop codon and trigger hydrolysis of the nascent chain. Upon dissociation of eRF3, 80S ribosomes are recycled by recruitment of the ATPase ABCE1 to regenerate free $40 \mathrm{~S}$ and $60 \mathrm{~S}$ subunits $^{20}$. This process maintains ribosome homeostasis by promoting additional rounds of translation initiation. Following $80 \mathrm{~S}$ ribosome dissociation, the free $60 \mathrm{~S}$ subunit may re-enter a new round of translation by binding a $48 \mathrm{~S}$ pre-initiation complex to form an elongation competent $80 \mathrm{~S}$. Alternatively, it may bind an empty 40S subunit to form a vacant mRNA-free $80 \mathrm{~S}$ monosome. A third possibility is that post-termination $60 \mathrm{~S}$ subunits bind eIF6 to maintain the cytoplasmic pool of free ribosomal subunits in a translationally inactive state.

This begs the question of how translationally inactive eIF6-bound 60S subunits are recycled back into active translation. Genetically, depletion of SBDS and EFL1 reduces global protein synthesis due to the defect in ribosomal subunit joining caused by eIF6 retention on the intersubunit face of the $60 \mathrm{~S}$ subunit ${ }^{7,13,15}$. While SBDS and EFL1 are known to release eIF6 during the final cytoplasmic step in nascent $60 \mathrm{~S}$ maturation, the marked reduction in protein synthesis in SBDS and EFL1-deficient cells suggested to us that these factors may have a broader role as general release factors that liberate rebound eIF6 in a number of different contexts such as during post-termination ribosome recycling. 
Although eIF6 was shown to bind to free 60S subunits by immunoblotting of mammalian cell extracts fractionated by sucrose gradient sedimentation ${ }^{1}$, the stoichiometry of this interaction in vivo remained unclear. In this study, we show that increasing the dose of eIF6 in vivo alters ribosome homeostasis by sequestering all free post-termination cytoplasmic 60S subunits, impairing ribosomal subunit joining and reducing $80 \mathrm{~S}$ assembly. The subunit joining defect induced by eIF6 overexpression mimics the consequences of SBDS or EFL1 deficiency in SDS patient cells, Dictyostelium, mice and zebrafish ${ }^{8,9,13,37}$ and is exacerbated by concomitant depletion of either SBDS or EFL1. Our data therefore suggest that increasing the dose of eIF6 alters ribosome homeostasis by exceeding the capacity of endogenous SBDS and EFL1 to evict eIF6 from dynamically recycling 60S subunits.

Our findings suggest that the inability to dynamically upregulate recycling of post-termination ribosomes back into active translation at key time points during development may be a critical facet of SDS pathogenesis. This is exemplified by the defect in erythroid differentiation we observed in mice expressing an increased dosage of eIF6. Our model provides a more satisfactory explanation of why diverse mosaic somatic genetic events, including point mutations, interstitial deletion and reciprocal chromosomal translocation involving EIF6 may confer a selective advantage in SBDS-deficient haematopoietic cells ${ }^{15}$ by disrupting the expression of eIF6 or its interaction with cytoplasmic (but not nuclear) 60S subunits, thus still preserving ribosome biogenesis. Indeed, SDS-related somatic EIF6 missense mutations that reduce eIF6 dosage or binding to cytoplasmic 60S subunits suppress the ribosome assembly and protein synthesis defects across multiple SBDS-deficient species including yeast, Dictyostelium, Drosophila and human cells ${ }^{15}$. Taken together, 
these genetic and biochemical data support a major role for SBDS and EFL1 in regulating cytoplasmic ribosome homeostasis and translational control.

As our transgenic mice overexpressing eIF6 recapitulate the defect in ribosome assembly observed in SDS, this model may provide a tool to further dissect SDS pathogenesis. Similar to germline depletion of Sbds or Efl1 in mice ${ }^{13,37,44,45}$, high doses of eIF6 are not systemically tolerated. However, future studies combining the EIF6 transgene with tissue-specific tetracycline transactivator mouse strains will bypass this limitation, harnessing the full potential of this model. Finally, our inducible eIF6 transgenic mouse model may find utility in the development of therapeutic strategies to restore cytoplasmic ribosome homeostasis in SDS by modulating the rebinding of eIF6 to cytoplasmic 60 S subunits. 


\section{MATERIALS AND METHODS}

\section{Generation of transgenic eIF6 mouse strain}

Gibson assembly was used to clone a full-length human EIF6 cDNA containing Kozak sequence (5'-ATCACG-3') into the EcoRI site of $\mathrm{pBS} 31$ vector, which was in turn used to target the KH2 embryonic stem (ES) cell line ${ }^{34}$. The engineered ES cells were injected into E3.5 C57BL/6 blastocysts to generate chimeric mice. Mice were backcrossed into the C57BL/6 background for at least three generations. PCR was used to genotype the Rosa26 locus (5'-AAAGTCGCTCTGAGTTGTTAT-3'; 5'GCGAAGAGTTTGTCCTCAACC-3'; 5'-GGAGCGGGAGAAATGGATATG-3'; WT product: $600 \mathrm{bp}$; Insert product: $300 \mathrm{bp}$ ) and the Collal locus (5'TCCCTCACTTCTCATCCAGATATT-3'; 5'AGTCTTGGATACTCCGTGACCATA-3'; 5'GGACAGGATAAGTATGACATCATCAA-3'; WT product: 1092 bp; Insert product: $455 \mathrm{bp}$ ). The EIF6 transgene was induced in vivo by administering Dox in the food (ssniff-Spezialdiäten $\mathrm{GmbH} ; 2000 \mathrm{mg} / \mathrm{kg}$ ). Mice were maintained in specific pathogen-free conditions and all procedures were performed according to the United Kingdom Home Office regulations. All experiments were performed using adult (8-12 weeks old) female and male mice with littermate controls.

\section{Peripheral blood analysis}

Peripheral blood was collected from the tail vein into Microvette ${ }^{\circledR} 500 \mathrm{~K} 3 \mathrm{E}$ tubes (Sarstedt) and cellularity analysed using a Woodley ABC blood counter.

\section{Histopathology}


Organs for histopathological analysis were fixed in $4 \%$ formaldehyde (Genta Medical, UK) followed by paraffin embedding and sectioning. Sections were stained with Hematoxylin-Eosin (Merck) for microscopic examination. FACS-purified erythroid precursors were transferred onto slides using a cytospin centrifuge and stained with May-Grünwald and Giemsa solutions (Merck). Morphological examination was performed using AxioImager Z2 Upright Wide-field Microscope (Zeiss).

\section{Flow cytometry}

We isolated bone marrow cells by crushing hips, femurs and tibias in PBS (Thermo Fisher Scientific) supplemented with foetal calf serum (FCS; $2 \%$; Thermo Fisher Scientific) and EDTA (2 mM; Thermo Fisher Scientific). Isolated cells were filtered through a $70 \mu \mathrm{m}$ cell strainer (Thermo Fisher Scientific). Antibody labelling was performed in PBS (+2\% FCS) for $30 \mathrm{~min}$ on ice. Antibodies are listed in the Supplementary Table 1. Erythrocytes were removed from peripheral blood by Dextran sedimentation (2\% in PBS; Merck) and ACK lysis buffer (Thermo Fisher Scientific) before antibody labelling. Experiments were performed using FACSARIA III cell sorter (BD Biosciences) and LSRFortessa flow cytometer (BD Biosciences), and analysed using FlowJo software (Tree Star, v10.1r7).

\section{Imaging flow cytometry}

Sample preparation was performed as previously described ${ }^{41}$. Briefly, $10 \times 10^{6}$ unfractionated bone marrow cells were fixed using formaldehyde (4\%; Alfa Aesar) for $15 \mathrm{~min}$ at room temperature. Following two washes with PBS, the cell pellet was cooled on ice for $15 \mathrm{~min}$, and permeabilised using ice-cold acetone (a cycle of 50\%- 
100\%-50\%). Following a wash with PBS (+2\% FCS), cells were stained for surface markers. Finally, $10 \times 10^{6}$ cells were resuspended in $100 \mu \mathrm{L}$ PBS supplemented with DRAQ5 (2.5 $\mu \mathrm{M}$; BioLegend), with acquisition performed on an ImageStream ${ }^{\circledR} \mathrm{X}$ Mark II Imaging Flow Cytometer (Merck) using a 40 x objective lens. Approximately 50000 events per sample were collected, and data analysis was performed using the associated Image Data Exploration and Analysis software (IDEAS; v.6.2; Merck).

\section{Cell isolation and culture}

c-Kit+ bone marrow cells were enriched using CD117 MicroBeads and MACS separation columns (Miltenyi Biotec), and cultured in OptiMEM I reduced Serum Media (Thermo Fisher Scientific), supplemented with FCS (10\%), penicillin/streptomycin (P/S, Life Technologies), $\beta$-mercaptoethanol (50 $\mu \mathrm{M}$; Thermo Fisher Scientific), murine stem cell factor (mSCF; $100 \mathrm{ng} / \mathrm{mL}$, PeproTech), murine interleukin 3 (mIL-3; $10 \mathrm{ng} / \mathrm{mL}$, PeproTech) and murine granulocyte-colony stimulating factor (mG-CSF; $10 \mathrm{ng} / \mathrm{mL}$, PeproTech) \pm Dox $(1 \mu \mathrm{g} / \mathrm{mL}$; Merck). Biotinylated antibodies and Anti-Biotin MicroBeads (Miltenyi) were used for lineage depletion. In vitro erythroid culture was performed as previously described ${ }^{46}$. Briefly, 1-2.5 $\times 10^{5} \mathrm{CFU}-\mathrm{E} /$ proerythroblasts isolated from Dox-treated mice were seeded on fibronectin-coated ( $2 \mu \mathrm{g} / \mathrm{mL}$; Merck) 48-well plates in Iscove's modified Dulbecco's medium (IMDM; Thermo Fisher Scientific) containing FCS (15\%), bovine serum albumin (BSA; $1 \%$; Stem Cell Technologies), mSCF (10 ng/mL), recombinant human erythropoietin (10 U/mL; Cell Signaling Technology), human recombinant insulin (100 $\mu \mathrm{g} / \mathrm{mL}$; Merck), recombinant human insulin-like growth factor 1 (hIGF1; $100 \mathrm{ng} / \mathrm{mL}$; Thermo Fisher Scientific), holo-transferrin (200 $\mu \mathrm{g} / \mathrm{mL}$; Merck), Lglutamine (2 mM; Merck), $\beta$-mercaptoethanol $(50 \mu \mathrm{M})$ and $\mathrm{P} / \mathrm{S}$. The following day, 
culture media was replaced with differentiation media consisting of IMDM, FCS (20 \%), $\beta$-mercaptoethanol $(50 \mu \mathrm{M}), \mathrm{P} / \mathrm{S}$ and L-glutamine $(2 \mathrm{mM})$. Homoharringtoninesupplemented differentiation media was used to assess the enucleation of prospectively purified orthochromatic erythroblasts.

\section{Transplantation assays}

Non-competitive transplantations were performed by injecting $5 \times 10^{6}$ freshly isolated unfractionated bone marrow cells in $250 \mu \mathrm{L}$ PBS (+2\% FCS) into the tail vein of lethally irradiated ( $2 \mathrm{x} 500$ cGY) congenic (CD45.1) wild-type recipients. Reconstituted mice were allowed to recover for two weeks before Dox administration.

\section{Protein synthesis rate measurement}

O-propargyl-puromycin (OP-puro) labelling experiments were performed as previously described ${ }^{47}$. Briefly, OP-puro (50 mg/kg in $200 \mu \mathrm{L}$ PBS; Jena Bioscience) was injected intraperitoneally and bone marrow cells were isolated after $1 \mathrm{hr} .3 \times 10^{6}$ cells were fixed with formaldehyde (4\%) for $15 \mathrm{~min}$ at room temperature. Following two washes with PBS (+2\% FCS), cells were stained with antibodies against cell surface markers. Stained cells were permeabilised using PBS supplemented with saponin (0.1\%; Merck) and FCS (2\%). The Click reaction was performed using the Click-iT $^{\mathrm{TM}}$ Plus OPP Alexa Fluor ${ }^{\mathrm{TM}} 488$ Protein Synthesis Assay Kit according to manufacturer's instructions (Thermo Fisher Scientific).

\section{Polysome profiling experiments}

Equal numbers of c-Kit+ bone marrow cells were expanded in the presence of doxycycline for 24 hours and treated with cycloheximide (CHX; $100 \mu \mathrm{g} / \mathrm{mL}$; Merck) 
for $8 \mathrm{~min}$ at $37^{\circ} \mathrm{C}$ before harvesting by centrifugation. Cells were washed twice with ice-cold PBS supplemented with CHX $(100 \mu \mathrm{g} / \mathrm{mL})$ and lysed for $30 \mathrm{~min}$ on ice in 'standard' lysis buffer (20 mM Hepes $\mathrm{pH} 7.5,50 \mathrm{mM} \mathrm{KCl}, 10 \mathrm{mM} \mathrm{Mg}\left(\mathrm{CH}_{3} \mathrm{COO}\right)_{2}$, $100 \mu \mathrm{g} / \mathrm{mL}$ CHX, cOmplete ${ }^{\mathrm{TM}}$ EDTA-free Protease Inhibitor Cocktail (Merck), RNaseOUT recombinant ribonuclease inhibitor (200 U/mL; Thermo Fisher Scientific) and IGEPAL ${ }^{\circledR}$ CA-630 (0.5\%; Merck), Dithiothreitol (DTT; 2 mM; Merck). The lysate was cleared by centrifugation $\left(18000 \mathrm{~g}\right.$ for $8 \mathrm{~min}$ at $\left.4{ }^{\circ} \mathrm{C}\right)$, and loaded onto a 5$45 \%$ (w/v) sucrose gradient (prepared in $20 \mathrm{mM}$ Hepes pH 7.5, $50 \mathrm{mM} \mathrm{KCl,} 10 \mathrm{mM}$ $\mathrm{Mg}\left(\mathrm{CH}_{3} \mathrm{COO}\right)_{2}, 100 \mu \mathrm{g} / \mathrm{mL} \mathrm{CHX}$ and cOmplete ${ }^{\mathrm{TM}}$ EDTA-free Protease Inhibitor Cocktail) prepared in a polypropylene centrifuge tube $(14$ x $95 \mathrm{~mm}$; Beckman Coulter). A Gradient Master (Biocomp) was used to prepare the sucrose gradients. After centrifugation (285, $000 \mathrm{~g}$ for $2 \mathrm{~h}$ at $4{ }^{\circ} \mathrm{C}$ using a Beckman SW40Ti rotor), polysome profiles were recorded using an Äktaprime plus chromatography system (GE Healthcare). Proteins were precipitated with trichloroacetic acid (25\% (vol/vol); $15 \mathrm{~min}$ on ice). Following centrifugation at $18000 \mathrm{~g}$ for $5 \mathrm{~min}$ at $4{ }^{\circ} \mathrm{C}$, protein precipitates were washed with ice-cold acetone. After drying at room temperature, protein pellets were resuspended in 1x NuPAGE LDS Sample Buffer (Thermo Fisher Scientific). Vacant 80S monosomes were dissociated in $20 \mathrm{mM}$ Hepes pH 7.5, 200 $\mathrm{mM} \mathrm{KCl}, 10 \mathrm{mM} \mathrm{Mg}\left(\mathrm{CH}_{3} \mathrm{COO}\right)_{2}, 100 \mu \mathrm{g} / \mathrm{mL}$ CHX, cOmplete ${ }^{\mathrm{TM}}$ EDTA-free Protease Inhibitor Cocktail (Merck), 200 U/mL RNaseOUT, $0.5 \%$ IGEPAL® CA-630 and 2 mM DTT.

\section{Purification of recombinant SBDS and EFL1 proteins}

SBDS and EFL1 proteins were purified as previously described ${ }^{13}$. 


\section{eIF6 release assay}

Preparation of mature 80S ribosomes. Expanded mouse c-Kit+ bone marrow cells were lysed in 'standard' lysis buffer (20 mM Hepes pH 7.5, $50 \mathrm{mM} \mathrm{KCl,} 10 \mathrm{mM}$ $\mathrm{Mg}\left(\mathrm{CH}_{3} \mathrm{COO}\right)_{2}$, supplemented with cOmplete ${ }^{\mathrm{TM}}$ EDTA-free Protease Inhibitor Cocktail, $200 \mathrm{U} / \mathrm{mL}$ RNaseOUT inhibitor, $0.5 \%$ IGEPAL ${ }^{\circledR}$ CA-630 and $2 \mathrm{mM}$ DTT). A total of $150 \mathrm{~A}_{260}$ units of lysate was loaded on six sucrose gradients, and fractions corresponding to $80 \mathrm{~S}$ monosomes were collected and further concentrated by centrifuging $30 \mathrm{~min}$ at $80000 \mathrm{~g}$ in a Beckman MLA-80 rotor fitted in an Optima MAX-XP ultracentrifuge. The sedimented $80 \mathrm{~S}$ particles were resuspended in 'standard' buffer and aliquots stored at $-80^{\circ} \mathrm{C}$.

Preparation of exogenous eIF6. c-Kit+ bone marrow cells isolated from transgenic eIF6 mice (genotype $[M 2-r t T A / M 2-r t T A][E I F 6 /+]$ ) were expanded and treated with doxycycline for $24 \mathrm{~h}$ to induce eIF6 overexpression. Cells were then harvested and lysed in 'dissociation' lysis buffer (20 mM Hepes pH 7.5, $500 \mathrm{mM} \mathrm{KCl,} 2 \mathrm{mM}$ $\mathrm{Mg}\left(\mathrm{CH}_{3} \mathrm{COO}\right)_{2}$ supplemented with $100 \mu \mathrm{g} / \mathrm{mL}$ CHX, cOmplete ${ }^{\mathrm{TM}}$ EDTA-free Protease Inhibitor Cocktail, $200 \mathrm{U} / \mathrm{mL}$ RNaseOUT inhibitor, $0.5 \%$ IGEPAL ${ }^{\circledR}$ CA630 and $2 \mathrm{mM}$ DTT). A total of $29 \mathrm{~A}_{260}$ units of lysate was run on a single sucrose gradient, and the free fraction, which contains the vast majority of cellular eIF6 but is devoid of ribosomes, was collected and aliquots stored at $-80^{\circ} \mathrm{C}$.

In vitro eIF6 release assay. In the first part of the assay, $10 \mathrm{uL}\left(1.25 \mathrm{~A}_{260}\right.$ units $)$ of mature $80 \mathrm{~S}$ particles were mixed with $100 \mathrm{uL}$ of exogenous eIF6 in 'dissociation' buffer. The reaction mix was then incubated at $37^{\circ} \mathrm{C}$ for $15 \mathrm{~min}$ both to promote the dissociation of the mature $80 \mathrm{~S}$ particles into $40 \mathrm{~S}$ and $60 \mathrm{~S}$ subunits, and to allow the binding of the exogenous eIF6 to $60 \mathrm{~S}$ subunits. The amount of eIF6 supplied was optimised empirically to be in slight excess over $60 \mathrm{~S}$ subunits, thus saturating the 
available $60 \mathrm{~S}$ subunits without a significant accumulation in the free fraction. In the second part of the protocol, the reaction mix was diluted with $500 \mathrm{uL}$ of prewarmed KCl-free buffer (20 mM Hepes pH 7.5, $\left.10 \mathrm{mM} \mathrm{Mg}\left(\mathrm{CH}_{3} \mathrm{COO}\right)_{2}\right)$, and incubated at 37 ${ }^{\circ} \mathrm{C}$ for 5 min to allow reassembly of $80 \mathrm{~S}$ particles. Since the joining of $40 \mathrm{~S}$ and $60 \mathrm{~S}$ subunits into $80 \mathrm{~S}$ particles is proportional to the release of eIF6 from $60 \mathrm{~S}$ subunits, this experimental strategy allows the assessment of eIF6 release based on quantification of $80 \mathrm{~S}$ to $60 \mathrm{~S}$ ratio. The reaction mix was split equally into two tubes that were supplied either with $1 \mathrm{mM}$ GTP or $1 \mathrm{mM} \mathrm{GTP}+1250 \mathrm{nM}$ SBDS $+600 \mathrm{nM}$ EFL1. Following $1 \mathrm{~h}$ incubation at $25^{\circ} \mathrm{C}$, the reaction mixes were cooled down on ice, and loaded on sucrose gradients prepared in 'standard' buffer conditions.

\section{Electron cryo-microscopy sample preparation and data collection}

c-Kit+ bone marrow cells were isolated from control mice that do not harbour EIF6 transgene, and expanded keeping cell concentration below one million cells per $\mathrm{mL}$. CHX-treated cells were lysed in 'standard' lysis buffer as described in 'Polysome profiling experiments'. Following sucrose gradient sedimentation, 60S subunits from multiple gradients were pooled, sedimented by centrifugation (45 min at $80000 \mathrm{~g}$ in an MLA-80 rotor), resuspended in $20 \mathrm{mM}$ HEPES $\mathrm{pH} 7.5,50 \mathrm{mM} \mathrm{KCl}, 5 \mathrm{mM}$ $\mathrm{Mg}\left(\mathrm{CH}_{3} \mathrm{COO}\right)_{2}$ at a concentration of $100 \mathrm{mM}$, and stored at $-80{ }^{\circ} \mathrm{C} .60 \mathrm{~S}$ ribosomal subunits were thawed on ice and centrifuged in a benchtop centrifuge for 10 minutes at $20000 \mathrm{~g}$ and the supernatant was carefully recovered. EM grids were prepared by depositing $3 \mu \mathrm{l}$ of $60 \mathrm{~S}$ subunits at $100 \mathrm{nM}$ to freshly glow-discharged Quantifoil $\mathrm{R}$ 1.2/1.3 holey carbon grids (PELCO easyGlow). Grids were then blotted with a Vitrobot Mark IV (FEI company) using the following parameters: blot time $1 \mathrm{~s}$, blot force -7 , wait time $10 \mathrm{~s}$, no drain time. Blotted grids were finally vitrified in liquid 
ethane and stored in liquid nitrogen. Grids were screened on a Tecnai T12 microscope (FEI Company) and data acquisition performed under low-dose conditions on a Titan Krios microscope (FEI Company) operated at $300 \mathrm{kV}$ over $24 \mathrm{~h}$. The dataset was recorded on a Falcon III detector (FEI Company) at a nominal magnification of 75,000x (effective pixel size of $1.10 \AA$ on the object scale) with a defocus range of -0.8 to $-3.2 \mu \mathrm{m}$ and a total dose of $\sim 77 \mathrm{e}-/ \AA^{2}$ accumulated over $2 \mathrm{~s}$ exposures in 38 fractions. The acquisition of 3024 movies was performed semi-automatically using EPU software (FEI Company).

\section{Electron cryo-microscopy data processing}

Data processing was handled within the RELION software package ${ }^{48-50}$. Movies were first corrected for motion using Motioncor $2^{51}$ and CTF was estimated by CTFFIND $^{52}$. Particles were then picked using the Laplacian-of-Gaussian (LoG) filter, extracted and 2D classified in RELION. 3D classification was then performed on selected 2D classes to further discard non-ribosomal and contaminating $80 \mathrm{~S}$ particles. The $60 \mathrm{~S}$ ribosomal subunit-containing class was selected for 3D autorefinement to generate a consensus map. Masking and auto-sharpening was done through post-processing in RELION to obtain the final high-resolution map.

To quantify the proportion of eIF6-bound ribosomal particles, we made use of a combination of particle subtraction and 3D masked classifications in RELION (Figure 1B). We first focused on the L1-stalk to sort particles relative to their maturation state. We generated a mask around the L1-stalk and the tRNA E-site from the consensus map and used it in 3D masked classification, leading to the isolation of mature ribosomal particles ( $88 \%$ of consensus-refined particles). We then generated a soft-edged mask around the area of the eIF6 binding site from the consensus map as 
an input. Signal outside this mask was subtracted in the newly obtained mature ribosomal particles subset. We finally generated 3D classes focusing on the area inside the mask. 4 classes were obtained, of which 3 showed clear density inside the masked area indicating the unequivocal presence of eIF6 and were then pooled for quantification ( $83 \%$ of mature ribosomal particles).

\section{Immunoblotting}

Proteins in 1x NuPAGE LDS sample buffer (with $50 \mathrm{mM}$ DTT) were incubated at 80 ${ }^{\circ} \mathrm{C}$ for 10 min and run on NuPAGE Bis-Tris polyacrylamide gels in NuPAGE MOPS SDS running buffer (Thermo Fisher Scientific). The iBlot 2 gel transfer device (Thermo Fisher Scientific) was used to transfer proteins to nitrocellulose membranes. Membranes were blocked in $5 \%$ milk in PBS supplemented with $0.1 \%$ tween (NBS Biologicals) for $1 \mathrm{~h}$, and subsequently incubated with appropriate primary antibodies overnight at $4{ }^{\circ} \mathrm{C}$ on a shaker. After $3 \times 10$ min washes with PBS-tween, the blots were incubated with the appropriate secondary horseradish peroxidase-conjugated antibody at room temperature for $1 \mathrm{~h}$ followed by detection using the SuperSignal West Pico PLUS reagents (Thermo Fisher Scientific). For a full list of antibodies, see

\section{Supplementary Table 2.}

\section{Subcellular fractionation}

$1 \times 10^{6}$ freshly isolated bone marrow cells from Dox-treated mice were washed twice with ice-cold PBS, and resuspended in $0.5 \mathrm{~mL}$ of 'standard' lysis buffer $(20 \mathrm{mM}$ Hepes pH 7.5, $50 \mathrm{mM} \mathrm{KCl}, 10 \mathrm{mM} \mathrm{Mg}\left(\mathrm{CH}_{3} \mathrm{COO}\right)_{2}$, cOmplete ${ }^{\mathrm{TM}}$ EDTA-free Protease Inhibitor Cocktail, $0.5 \%$ IGEPAL ${ }^{\circledR}$ CA-630, and $2 \mathrm{mM}$ DTT. Following $30 \mathrm{~min}$ incubation on ice, lysates were centrifuged for $5 \mathrm{~min}$ at $7000 \mathrm{~g}$ to pellet the nuclei, 
while supernatants representing the cytosolic fraction were collected. Following a wash with ice-cold PBS and centrifugation as above, the nuclear pellet was resuspended in $0.5 \mathrm{~mL}$ of ice-cold RIPA buffer supplied with $1 \mathrm{U} / \mathrm{mL}$ Benzonase (Merck), and incubated on a rotator for $1 \mathrm{~h}$ at $4{ }^{\circ} \mathrm{C}$. Following centrifugation for 5 min at $7000 \mathrm{~g}$ to pellet insoluble material, supernatant representing the nuclear fraction was collected. Finally, both fractions were resuspended in 1x NuPAGE LDS sample buffer with $50 \mathrm{mM}$ DTT.

\section{Quantitative real-time PCR}

Total RNA was isolated from FACS-purified cells using the RNeasy mini kit (Qiagen). cDNA was transcribed with SuperScript III reverse trancriptase (Thermo Fisher Scientific). Real-time PCR reactions were performed using the SsoFast ${ }^{\mathrm{TM}}$ EvaGreen $^{\circledR}$ Supermix (Bio-Rad) and ABI 7900HT fast Real-time PCR system (Thermo Fisher Scientific). Primers are listed in Supplementary Table 3.

\section{Light microscopy}

Drosophila was maintained using standard culture techniques. All crosses were performed at $25{ }^{\circ} \mathrm{C}$. Fly strains and genotypes are described in Supplementary Tables 4 and 5. Whole Drosophila samples were collected at 1, 3, 5, and 11 days after egg laying (AEL). Larvae were fixed with 4\% paraformaldehyde and adult flies were frozen before photography. For the imaging of fly eyes, two to four day old Drosophila adults were frozen at $-20{ }^{\circ} \mathrm{C}$ for one hour. Both whole fly and adult eye photographs were collected using a Nikon SMZ18 microscope with NIS-Elements D (version 4.40). 


\section{Scanning Electron Microscopy}

Drosophila adult eye samples were prepared as described ${ }^{53}$. Samples were viewed on a Philips XL30 scanning electron microscope.

\section{Immunostaining}

Drosophila wing discs dissected from third instar larvae in culture medium (Drosophila M3 media (Sigma), 10 \% FCS (Sigma) and P/S (Sigma) were collected within 10 min into culture medium containing $50 \mu \mathrm{M}$ of OP-Puro (Invitrogen) and kept in a $25{ }^{\circ} \mathrm{C}$ incubator for $30 \mathrm{~min}$. Wing discs were then washed twice with icecold PBS (Invitrogen) with 1\% BSA (Sigma) and $100 \mu \mathrm{g} / \mathrm{ml} \mathrm{CHX} \mathrm{(Sigma).} \mathrm{Wing}$ discs were fixed and permeabilised using the Cytofix/Cytoperm Fixation Permeabilization Kit (BD Biosciences). Azide-alkyne cycloaddition was performed using the Click-iT Cell Reaction Buffer Kit (Invitrogen) with azide conjugated to Alexa Fluor 596 at $5 \mu \mathrm{M}$ final concentration. Following a 30 min reaction, wing discs were washed three times in PBS and mounted on slides in medium containing DAPI (Vector). Images were collected on a Zeiss LSM710 confocal system and imported to Image J 10.4 (Image J) and Photoshop (Adobe 2020), and adjusted for brightness and contrast uniformly across entire fields.

\section{ACKNOWLEDGEMENTS}

This work was supported by the Swedish Childhood Cancer Fund (PDS13/001, to PJ), the Swedish Research Council (2014-06807, to PJ), a Specialist Programme from Bloodwise (12048, to AJW), the UK Medical Research Council (MC_U105161083, to AJW), a Wellcome Trust strategic award to the Cambridge Institute for Medical 
Research (100140, to AJW), a core support grant from the Wellcome Trust and MRC to the Wellcome Trust-Medical Research Council Cambridge Stem Cell Institute, the Connor Wright Project, Ted's Gang and the Cambridge National Institute for Health Research Biomedical Research Centre. C.C.W. acknowledges funding from a Wellcome Intermediate Fellowship (Grant Number: 105914/Z/14/Z) and the Kay Kendall Leukaemia Fund. We thank Dr. D. Y. Chirgadze for assistance with data collection at the Cryo-EM Facility, Department of Biochemistry, University of Cambridge, funded by the Wellcome Trust (206171/Z/17/Z; 202905/Z/16/Z), the Departments of Biochemistry and Chemistry, the Schools of Biological Sciences and Clinical Medicine and the University of Cambridge. We thank R. Grenfell at the Cancer Research UK Cambridge Institute for assistance with imaging flow cytometry. The Cambridge NIHR BRC Cell Phenotyping Hub supported this research. We thank T. Hamilton, D. Pask, D. Kent, G. Giotopoulos, B. Huntly and A.R. Green for facilitating animal experiments. We thank M. Freeman, the Bloomington Drosophila Stock Center, NIG-Fly Stock Center and Vienna Drosophila RNAi Center for providing fly stocks.

\section{AUTHORSHIP}

Conflict-of-interest disclosure: The authors declare no competing financial interests. 


\section{FIGURE LEGENDS}

Figure 1. eIF6 maintains free mammalian 60S subunits in a translationally inactive state.

(A) Sucrose gradient sedimentation of eIF6 in cell extracts prepared from murine ckit+ bone marrow cells. The distribution of eIF6, Rp111 and Rps19 was visualised by immunoblotting.

(B) Cryo-EM classification scheme to quantify the frequency of eIF6-bound 60S subunits in the cytoplasm. See Material and Methods for further details.

(C) eIF6 binds the intersubunit face of free cytoplasmic 60S subunits. Crown views of the cryo-EM maps of native 60S-eIF6 complexes isolated from murine c-kit+ bone marrow cells. eIF6 is highlighted by the red colour.

(D) Atomic model for the murine 60S ribosomal subunit bound to human eIF6.

Figure 2. SBDS and EFL1 catalyse GTP-dependent release of rebound eIF6 from mature cytoplasmic $60 \mathrm{~S}$ ribosomal subunits.

(A) Sucrose gradient sedimentation of c-Kit + bone marrow cell extracts (without cycloheximide) lysed in $20 \mathrm{mM}$ Hepes $\mathrm{pH} 7.5,2 \mathrm{mM} \mathrm{Mg}\left(\mathrm{CH}_{3} \mathrm{COO}\right)_{2}$ and $500 \mathrm{mM}$ $\mathrm{KCl}$, and incubated for $10 \mathrm{~min}$ at $37^{\circ} \mathrm{C}$ to allow eIF6 rebinding. eIF6 was detected by immunoblotting.

(B) Schematic overview of in vitro eIF6 release assay. See Materials and Methods section for further details.

(C) Sucrose gradient sedimentation of reconstituted eIF6 release reaction mixes. Immunoblotting was used to detect eIF6. The ratio of $80 \mathrm{~S}$ monosomes to $60 \mathrm{~S}$ subunits is indicated. Shown is a representative experiment out of a total of two independent experiments. 
Figure 3. Genetic interactions between Sbds, Efl1 and $e I F 6$.

(A) Increased eIF6 dosage enhances the growth defects of Sbds-deficient Drosophila. Flies were photographed at 1, 3, 5 and 11 days after egg laid (AEL). Scale bar, $1 \mathrm{~mm}$. (B) Genetic interactions between Sbds, Efl1 and eIF6 in the Drosophila eye. Representative photomicrographs of adult eyes from flies with the indicated genotypes. EES, abbreviation of (eIF6/+, Efl $1^{R N A i} /+$, Sbds $\left.{ }^{R N A i} /+\right)$. Scale bar, $100 \mu \mathrm{m}$.

(C) Overexpression of eIF6 suppresses global protein synthesis in Drosophila wing disc cells. Third instar larval wing disc cells with the indicated genotypes were immunostained to reveal OP-Puro incorporation (red, grey). Posterior wing disc cells are marked with GFP; nucleus is blue (DAPI), scale bar: $100 \mu \mathrm{m}$.

Figure 4. eIF6 binds post-termination 60S subunits to prevent ribosomal subunit joining.

(A) Schematic overview of the transgenic Dox-inducible eIF6 overexpression system.

(B) Breeding strategy for graded overexpression of eIF6, with colour coding of indicated genotypes.

(C) Quantitative real-time PCR of EIF6 transcript levels ( $\mathrm{n}=3-4$ per genotype).

(D) eIF6 protein immunoblotting analysis in extracts from cultured c-Kit + bone marrow cells derived from the indicated mouse strains after $24 \mathrm{hr}$ of Dox induction.

(E, F). Sucrose gradient sedimentation of extracts (including cycloheximide) from cultured c-Kit + bone marrow cells derived from the indicated mouse strains. Dox induction, $24 \mathrm{hr}$. Buffers in (E) and (F) contain $50 \mathrm{mM}$ or $200 \mathrm{mM} \mathrm{KCl}$, respectively. Shown is representative of two independent experiments.

(G) Sucrose gradient sedimentation of extracts prepared in absence of magnesium to dissociate $80 \mathrm{~S}$ ribosomes and polysomes. 
(H) Quantification of the 60S:40S subunit ratios shown in (G) (n=3 per genotype). Student's $t$ test was used to determine statistical significance, and two-tailed $P$ values are shown. Error bars represent standard deviation.

\section{Figure 5. Increased eIF6 dosage impairs erythroblast enucleation in mice.}

(A) Increased eIF6 dosage causes macrocytic anemia. Haematological parameters including hemoglobin concentration, erythrocyte count and mean corpuscular volume (MCV) (n=12-15 per genotype) are shown over the indicated time-course of Dox induction for eIF $6^{\text {hi }}$ mice versus control.

(B) Reticulocyte counts ( $\mathrm{n}=3$ per genotype).

(C) Representative flow cytometry analysis of erythroid precursors in control versus eIF ${ }^{\text {hi }}$ bone marrow. Gated populations are designated 1-6 in red.

(D) Frequency of erythroid precursors in the bone marrow ( $n=7$ per genotype), corresponding to gated populations 1-6 in the flow cytometry analysis. Pro, proerythroblast; Baso, basophilic erythroblast; Poly, polychromatic erythroblast; Ortho, orthochromatic erythroblast; Retic, reticulocyte.

(E) Morphology of erythroid precursors, corresponding to populations 4-6 by flow cytometry.

(F) Representative images of enucleating erythroblasts, defined by Amnis ImageStream IDEAS gating strategy, shown in Supplementary Figure 9.

(G) Frequencies of enucleating erythroblasts within the late erythroblast population (corresponding to gate 6 in IDEAS gating strategy), in the bone marrow ( $n=4$ per genotype) after 2 weeks of Dox administration. Student's $t$ test was used to determine statistical significance, and two-tailed $P$ values are shown. Error bars represent standard deviation. 
Figure 6. Increased eIF6 dosage impairs erythroblast enucleation by attenuating protein synthesis.

(A) OP-Puro incorporation in the indicated bone marrow cells in vivo after two weeks of Dox administration ( $\mathrm{n}=3-4$ per genotype). Median fluorescence intensities were normalised against the respective control cell populations.

(B) Expression of eIF6 in CFU-E erythroid progenitor cells and erythroid precursors in vivo after two weeks of Dox treatment. Immunoblots are shown for eIF6 and Rps19 using extracts generated from identical numbers of the indicated bone marrow cells. Shown is representative of two independent experiments. CFU-E progenitor cells are defined as CD71+ TER-119- bone marrow cells.

(C) Total cellular nucleic acid content in vivo during terminal erythroid differentiation. Freshly isolated bone marrow cells ( $n=4$ per genotype) were stained with thiazole orange. Thiazole orange intensities are shown relative to CD44+ TER119- non-erythroid bone marrow cells.

(D) Enucleation of FACS-purified wild type orthochromatic erythroblasts in culture after 3,5 or $24 \mathrm{hr}$ treatment with homoharringtonine $(\mathrm{n}=3)$. Enucleation efficiency is expressed as the ratio of reticulocytes to orthochromatic erythroblasts. Student's $t$ test was used to determine statistical significance, and two-tailed $P$ values are shown. Error bars represent standard deviation.

Figure 7. Model illustrating how dynamic rebinding of eIF6 couples ribosome maturation and translation. eIF6 functions as a ribosome anti-association factor to hold nascent pre-60S and mature post-termination $60 \mathrm{~S}$ subunits in a translationally inactive state. SBDS and EFL1 couple nascent 60S subunit maturation and ribosome recycling by acting as general eIF6 release factors. 


\section{SUPPLEMENTARY FIGURE LEGENDS}

\section{Supplementary Figure 1. Fourier shell correlation curves of the cryo-EM data}

set. Fourier shell correlation curves of both solvent masked and unmasked final maps indicating maximum resolution at 0.143 'gold standard' threshold.

\section{Supplementary Figure 2. Genetic interaction between eIF6 and Sbds.}

Representative scanning electron microscopy images showing the Drosophila eye phenotypes in the indicated genotypes. $\mathrm{n}=3$.

\section{Supplementary Figure 3. Dox administration has no acute impact on weight gain}

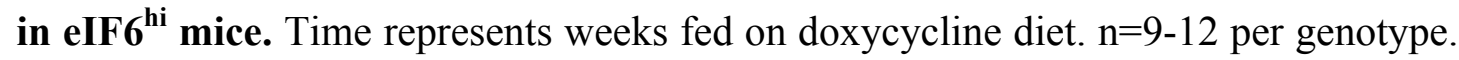
Student's $t$ test was used to determine statistical significance, and two-tailed $P$ values are shown. Error bars represent standard deviation.

Supplementary Figure 4. Validation of EIF6 transgene expression in eIF6 ${ }^{\text {hi }}$ mice. (A) Quantitative real-time PCR analysis of EIF6 mRNA expression in LSK, preGM/GMP and preCFU-E/CFU-E progenitor cells isolated from adult mice after two weeks of doxycycline administration. ( $n=4$ per genotype).

(B) Sucrose gradient sedimentation of extracts from cultured c-Kit + bone marrow cells derived from the indicated mouse strains. Dox induction, $24 \mathrm{~h}$.

(C) Immunoblotting analysis to visualise eIF6, Sbds, Rpl11 and Rps19 across the sucrose density gradients shown in (B).

(D) Subcellular fractionation of freshly isolated unfractionated bone marrow cells from adult mice after two weeks of doxycycline administration. $\mathrm{C}=$ cytoplasmic fraction, $\mathrm{N}=$ nuclear fraction. $\mathrm{LSK}=$ Lineage- $\mathrm{Sca}-1+\mathrm{c}-\mathrm{Kit}+$, preGM$=$ pre- 
granulocyte-macrophage progenitor, $\mathrm{GMP}=$ granulocyte-macrophage progenitor, preCFU-E $=$ pre-colony-forming unit-erythroid progenitor. Student's $t$ test was used to determine statistical significance, and two-tailed $P$ values are shown. Error bars represent standard deviation.

Supplementary Figure 5. Peripheral blood analysis of eIF6 ${ }^{\text {hi }}$ mice after two weeks of doxycycline induction. $\mathrm{n}=12-15$ per genotype. Student's $t$ test was used to determine statistical significance and two-tailed $P$ values are shown. Error bars represent standard deviation.

\section{Supplementary Figure 6. Histological examination of the eIF6 ${ }^{\text {hi }}$ mice.}

(A) Representative bone marrow sections (40X).

(B) Spleen weight ( $\mathrm{n}=7$ per genotype).

(C) Representative spleen sections (40X).

Student's $t$ test was used to determine statistical significance, and two-tailed $P$ values are shown. Error bars represent standard deviation.

Supplementary Figure 7. Flow cytometry strategy to quantify bone marrow subpopulations.

\section{Supplementary Figure 8. Flow cytometric analysis of the haematopoietic phenotype of the eIF6 ${ }^{\text {hi }}$ mice.}
(A) Bone marrow cellularity and
(B) frequency of haematopoietic stem and progenitor cells in the bone marrow after two weeks of Dox administration ( $\mathrm{n}=7$ per genotype). 
(C) Frequency of erythroid precursor cells in the spleen after two weeks of Dox administration ( $\mathrm{n}=7$ per genotype).

(D) Representative in vitro differentiation culture of prospectively purified CFUE/proerythroblast cells $(n=2)$. Fresh cells were isolated from the bone marrow of Doxtreated IF6 $^{\text {hi }}$ mice, and depleted for TER-119, Gr-1, CD11b, CD4, CD8, B220, CD41, CD16/32, CD150 and Sca-1. Enriched cells were cultured with or without Dox.

HSC $=$ haematopoietic stem cell; $\mathrm{MPP}=$ multipotent progenitor; $\mathrm{pGM}=$ pregranulocyte-macrophage progenitor; GMP = granulocyte-macrophage progenitor, preMegE $=$ pre-megakaryocyte-erythroid progenitor, $\mathrm{MkP}=$ megakaryocyte progenitor, preCFU-E = pre-colony-forming unit-erythroid progenitor. Student's $t$ test was used to determine statistical significance, and two-tailed $P$ values are shown. Error bars represent standard deviation.

\section{Supplementary Figure 9. IDEAS strategy to visualise enucleating erythroblasts} in the bone marrow.

Supplementary Figure 10. The haematopoietic phenotype in eIF6 ${ }^{\text {hi }}$ mice is autonomous to the blood system.

(A) Overview of the transplantation strategy. Five million freshly isolated unfractionated bone marrow cells from uninduced control or eIF6 ${ }^{\text {hi }}$ mice were transplanted into the tail vein of lethally irradiated (2x $500 \mathrm{cGy}$ ) wild-type recipients (CD45.1). Two weeks after transplantation, Dox was administered to the recipient mice to induce expression of the EIF6 transgene, and peripheral blood cellularity was analysed at indicated time-points. 
(B) The number of erythrocytes and platelets, hemoglobin concentration and mean corpuscular volume (MCV) in the peripheral blood over time ( $\mathrm{n}=9-10$ per group).

(C) Donor cell reconstitution within the different white blood cell lineages after 16 weeks of Dox administration ( $\mathrm{n}=9-10$ per group). Student's $t$ test was used to determine statistical significance, and two-tailed $P$ values are shown. Error bars represent standard deviation. 
Supplementary Table 1. Antibodies and reagents used in flow cytometry.

Fluorochrome Cat\# Manufacturer Dilution

$\underline{\text { Bone marrow analysis }}$

\begin{tabular}{|c|c|c|c|c|}
\hline CD71 & FITC & 113806 & Biolegend & $1: 200$ \\
\hline CD44 & FITC & 553133 & BD Biosciences & $1: 200$ \\
\hline CD48 & FITC & 103404 & Biolegend & $1: 200$ \\
\hline CD41 & PE & $12-0411-83$ & eBioscience & $1: 200$ \\
\hline CD45.1 & $\mathrm{PE}$ & 110708 & Biolegend & $1: 200$ \\
\hline GR1 & PE-Cy5 (Lineage) & 108410 & Biolegend & $1: 400$ \\
\hline CD11b & PE-Cy5 (Lineage) & 101210 & Biolegend & $1: 400$ \\
\hline B220 & PE-Cy5 (Lineage) & 103210 & Biolegend & $1: 400$ \\
\hline CD3 & PE-Cy5 (Lineage) & 100310 & Biolegend & $1: 400$ \\
\hline Ter119 & PE-Cy5 (Lineage) & 116210 & Biolegend & $1: 400$ \\
\hline Ter119 & PE-Cy7 & $25-5921-82$ & eBioscience & $1: 400$ \\
\hline CD16/32 & PE-Cy7 & 101317 & Biolegend & $1: 200$ \\
\hline CD150 & APC & 115910 & Biolegend & $1: 200$ \\
\hline c-Kit & APC-eFluor780 & $47-1171-82$ & eBioscience & $1: 100$ \\
\hline Endoglin & Biotin & 120404 & Biolegend & $1: 200$ \\
\hline Sca-1 & Pacific blue & 122520 & Biolegend & $1: 200$ \\
\hline CD44 & Pacific blue & 103019 & Biolegend & $1: 200$ \\
\hline CD71 & BV421 & 113813 & Biolegend & $1: 200$ \\
\hline Streptavidin & QD605 & Q10101MP & Life Technologies & $1: 200$ \\
\hline
\end{tabular}

$\underline{\text { Peripheral blood analysis }}$

$\begin{array}{llll}\text { CD45.2 } & \text { FITC } & 109806 & \text { Biolegend }\end{array}$ 


$\begin{array}{lllll}\text { CD45.1 } & \text { PE } & 110708 & \text { Biolegend } & 1: 200 \\ \text { CD19 } & \text { PE-Cy7 } & 25-0193-82 & \text { eBioscience } & 1: 200 \\ \text { CD11b } & \text { APC } & 101212 & \text { Biolegend } & 1: 800 \\ \text { CD3 } & \text { Alexa Fluor }{ }^{\circledR} 700 & 100216 & \text { Biolegend } & 1: 400\end{array}$

Lineage depletion/enrichment

$\begin{array}{lllll}\text { CD71 } & \text { Biotin } & 113803 & \text { Biolegend } & 1: 200 \\ \text { Ter119 } & \text { Biotin } & 116204 & \text { Biolegend } & 1: 200 \\ \text { CD4 } & \text { Biotin } & 100404 & \text { Biolegend } & 1: 200 \\ \text { CD8a } & \text { Biotin } & 100704 & \text { Biolegend } & 1: 200 \\ \text { B220 } & \text { Biotin } & 103204 & \text { Biolegend } & 1: 200 \\ \text { CD16/32 } & \text { Biotin } & 101303 & \text { Biolegend } & 1: 200 \\ \text { CD41 } & \text { Biotin } & 133930 & \text { Biolegend } & 1: 200 \\ \text { Sca-1 } & \text { Biotin } & 108103 & \text { Biolegend } & 1: 200 \\ \text { Gr-1 } & \text { Biotin } & 108404 & \text { Biolegend } & 1: 200 \\ \text { CD11b } & \text { Biotin } & 101204 & \text { Biolegend } & 1: 200\end{array}$


Supplementary Table 2. Antibodies used in immunoblotting.
Cat\#
Manufacturer
Dilution

Primary antibodies

$\begin{array}{llll}\text { EIF6 } & \text { GTX117971 } & \text { GeneTex } & 1: 1000 \\ \text { GAPDH } & \text { G9545 } & \text { Merck } & 1: 10000 \\ \text { NMD3 } & \text { 16060-1-AP } & \text { Proteintech } & 1: 1000 \\ \text { RPS19 } & 15085-1 \text {-AP } & \text { Proteintech } & 1: 1000 \\ \text { RPL11 } & \text { 16277-1-AP } & \text { Proteintech } & 1: 1000 \\ \text { RPL7a } & 2415 & \text { CST } & 1: 1000 \\ \text { SBDS } & \text { GTX109168 } & \text { GeneTex } & 1: 1000 \\ \text { Lamin B1 } & 12987-1-\text { AP } & \text { Proteintech } & 1: 2000\end{array}$

$\underline{\text { Secondary antibodies }}$

$\begin{array}{lll}\text { Anti-rabbit IgG, HRP-linked } 7074 & \text { CST } & 1: 5000\end{array}$ 
Supplementary Table 3. Custom primers used for quantitative real-time PCR

\section{Gene}

$A c t b$

Eif6

(mouse)

EIF6

(Total: mouse + transgene)
Primer

5'-CCACAGCTGAGAGGCAAATC-3'

5'-CTTCTCCAGGGAGGAAGAGG-3'

5'-CCAAGTACCATTGCCACCAG-3'

5'-GGAAAATGAGCCAAAGTCCAGAG-3'

5'-AATGTCACCACCTGCAATGAC-3'

5'-TGTCTGAAGACTTCCACCTTGAG-3' 


\title{
Supplementary Table 4. Drosophila melanogaster strains.
}

\author{
$\begin{array}{lll}\text { Name Genotype Source } & \end{array}$ \\ da-GAL4 $\quad$ w $^{*} ;$ P\{GAL4-da.G32\}UH1 Bloomington Drosophila Stock \\ Center
Efl1 $^{\mathrm{RNAi}} \quad w^{1118} ; P\{G D 11381\} v 34884 / C y O \quad$ Vienna Drosophila RNAi
Center
En>GAL4 $\quad w^{1118} ; P\{e n 2.4-G A L 4\}$ e16E, P\{UAS- Bloomington Drosophila Stock $2 x E G F P\} A H 2$ Center

GMR-GAL4 $w^{*} ; P\{G A L 4-n i n a E . G M R\} 12 \quad$ M. Freeman

$\operatorname{Sbds}^{\mathrm{RNAi}} \quad w^{1118} ; ; p U A S-8549 R-4 \quad$ NIG-Fly

UAS-eIF6 $\quad w^{1118} ; ; p$ DAS-eIF6-FLAG A.J. Warren

UAS-Sbds $\quad w^{1118} ; ; p U A S-S b d s-F L A G \quad$ A.J. Warren 


\section{Supplementary Table 5. Drosophila melanogaster genotypes.}

Figure

Fig 3A

Fig 3A

Fig $3 \mathrm{~A}$

Fig 3A
Name

Control

$S b d s^{R N A i} /+$

eIF $6 /+$

eIF6/+, Sbds ${ }^{R N A i} /+$

$$
S b d s^{R N A i}
$$

$w^{1118} ; G M R-G A L 4 /+$

Fig 3B, Suppl Fig 2 Control

$w^{1118} ; ; d a-G A L 4 / U A S-e I F 6$

Fig 3B, Suppl Fig 2

$e I F 6 /+, S b d s^{R N A i} /+$

$w^{1118} ;$ GMR-GAL4/+; UAS-eIF6,UAS-

$S b d s^{R N A i} /+$

Fig 3B, Suppl Fig $2 \quad S b d s^{R N A i} /+$

$w^{1118} ;$ GMR-GAL4/+; UAS-Sbds ${ }^{R N A i} /+$

Fig 3B, Suppl Fig 2 eIF6/+

$w^{1118} ;$ GMR-GAL4/+; UAS-eIF6/+

Fig 3B

$$
\begin{gathered}
e I F 6 /+, E f l 1^{R N A i} /+\quad w^{1118} ; G M R-G A L 4 / U A S-E f l 1^{R N A i} ; U A S- \\
e I F 6 /+
\end{gathered}
$$


Fig 3B

Fig 3B

Fig 3B

Fig 3C

Fig 3C

Suppl Fig 2

Suppl Fig 2

eIF6/+,

$\operatorname{Sbds}{ }^{R N A i} / \mathrm{S} b d s$

$E n>G F P$ $w^{1118} ;$ GMR-GAL4/+; UAS-eIF6/UAS-

eIF6

$w^{1118} ;$ GMR-GAL4/UAS-Efl1 ${ }^{R N A i}$

$w^{1118} ;$ GMR-GAL4/UAS-Efl1 ${ }^{R N A i} ; U A S-$

eIF6,UAS-Sbds ${ }^{R N A i} /+^{i}$

$w^{1118}$; en2.4-GAL4, UAS-2xeGFP/+

$E n>G F P, e I F 6 /+$

$w^{1118}$; en2.4-GAL4, UAS-2xeGFP/+;

UAS-eIF6/+

$S b d s^{R N A i} / S b d s^{R N A i}$

$w^{1118} ;$ GMR-GAL4/+; UAS-

$S b d s^{R N A i} / S b d s^{R N A i}$

$w^{1118} ;$ GMR-GAL4/+; UAS-eIF6,UAS-

$S b d s^{R N A i} / U A S-S b d s$ 


\section{REFERENCES}

1. Ceci, M. et al. Release of eIF6 (p27BBP) from the 60S subunit allows $80 \mathrm{~S}$ ribosome assembly. Nature 426, 579-584 (2003).

2. Russell, D.W. \& Spremulli, L.L. Mechanism of action of the wheat germ ribosome dissociation factor: interaction with the $60 \mathrm{~S}$ subunit. Arch Biochem Biophys 201, 518-526 (1980).

3. Gartmann, M. et al. Mechanism of eIF6-mediated inhibition of ribosomal subunit joining. J Biol Chem 285, 14848-14851 (2010).

4. Basu, U., Si, K., Warner, J.R. \& Maitra, U. The Saccharomyces cerevisiae TIF6 gene encoding translation initiation factor 6 is required for $60 \mathrm{~S}$ ribosomal subunit biogenesis. Mol Cell Biol 21, 1453-1462 (2001).

5. Senger, B. et al. The nucle(ol)ar Tif6p and Efl1p are required for a late cytoplasmic step of ribosome synthesis. Mol Cell 8, 1363-1373 (2001).

6. Becam, A.M., Nasr, F., Racki, W.J., Zagulski, M. \& Herbert, C.J. Ria1p (Ynl163c), a protein similar to elongation factors 2, is involved in the biogenesis of the 60S subunit of the ribosome in Saccharomyces cerevisiae. Mol Genet Genomics 266, 454-462 (2001).

7. Menne, T.F. et al. The Shwachman-Bodian-Diamond syndrome protein mediates translational activation of ribosomes in yeast. Nat Genet 39, 486-495 (2007).

8. Finch, A.J. et al. Uncoupling of GTP hydrolysis from eIF6 release on the ribosome causes Shwachman-Diamond syndrome. Genes Dev 25, 917-929 (2011).

9. Wong, C.C., Traynor, D., Basse, N., Kay, R.R. \& Warren, A.J. Defective ribosome assembly in Shwachman-Diamond syndrome. Blood 118, 4305-4312 (2011).

10. Weis, F. et al. Mechanism of eIF6 release from the nascent $60 \mathrm{~S}$ ribosomal subunit. Nat Struct Mol Biol 22, 914-919 (2015).

11. Kargas, V. et al. Mechanism of completion of peptidyltransferase centre assembly in eukaryotes. Elife 8 (2019).

12. Boocock, G.R. et al. Mutations in SBDS are associated with ShwachmanDiamond syndrome. Nat Genet 33, 97-101 (2003).

13. Tan, S. et al. EFL1 mutations impair eIF6 release to cause ShwachmanDiamond syndrome. Blood 134, 277-290 (2019).

14. Warren, A.J. Molecular basis of the human ribosomopathy ShwachmanDiamond syndrome. Adv Biol Regul 67, 109-127 (2018).

15. Tan, S. et al. Somatic genetic rescue of a germline ribosome assembly defect. Nat Commun 12, 5044 (2021).

16. Kennedy, A.L. et al. Distinct genetic pathways define pre-malignant versus compensatory clonal hematopoiesis in Shwachman-Diamond syndrome. Nat Commun 12, 1334 (2021).

17. Shen, P.S. et al. Protein synthesis. Rqc2p and $60 \mathrm{~S}$ ribosomal subunits mediate mRNA-independent elongation of nascent chains. Science 347, 75-78 (2015).

18. Su, T. et al. Structure and function of Vms1 and Arb1 in RQC and mitochondrial proteome homeostasis. Nature 570, 538-542 (2019).

19. Alkalaeva, E.Z., Pisarev, A.V., Frolova, L.Y., Kisselev, L.L. \& Pestova, T.V. In vitro reconstitution of eukaryotic translation reveals cooperativity between release factors eRF1 and eRF3. Cell 125, 1125-1136 (2006). 
20. Pisarev, A.V. et al. The role of ABCE1 in eukaryotic posttermination ribosomal recycling. Mol Cell 37, 196-210 (2010).

21. Shoemaker, C.J. \& Green, R. Kinetic analysis reveals the ordered coupling of translation termination and ribosome recycling in yeast. Proc Natl Acad Sci U $S A$ 108, E1392-1398 (2011).

22. Skabkin, M.A. et al. Activities of Ligatin and MCT-1/DENR in eukaryotic translation initiation and ribosomal recycling. Genes Dev 24, 1787-1801 (2010).

23. Heuer, A. et al. Structure of the 40S-ABCE1 post-splitting complex in ribosome recycling and translation initiation. Nat Struct Mol Biol 24, 453-460 (2017).

24. Tzamarias, D., Roussou, I. \& Thireos, G. Coupling of GCN4 mRNA translational activation with decreased rates of polypeptide chain initiation. Cell 57, 947-954 (1989).

25. Ashe, M.P., De Long, S.K. \& Sachs, A.B. Glucose depletion rapidly inhibits translation initiation in yeast. Mol Biol Cell 11, 833-848 (2000).

26. Surks, M.I. \& Berkowitz, M. Rat hepatic polysome profiles and in vitro protein synthesis during hypoxia. Am J Physiol 220, 1606-1609 (1971).

27. Uesono, Y. \& Toh, E.A. Transient inhibition of translation initiation by osmotic stress. J Biol Chem 277, 13848-13855 (2002).

28. Pisareva, V.P., Skabkin, M.A., Hellen, C.U., Pestova, T.V. \& Pisarev, A.V. Dissociation by Pelota, Hbs1 and ABCE1 of mammalian vacant $80 \mathrm{~S}$ ribosomes and stalled elongation complexes. EMBO J 30, 1804-1817 (2011).

29. Mills, E.W., Wangen, J., Green, R. \& Ingolia, N.T. Dynamic Regulation of a Ribosome Rescue Pathway in Erythroid Cells and Platelets. Cell Rep 17, 1-10 (2016).

30. Groft, C.M., Beckmann, R., Sali, A. \& Burley, S.K. Crystal structures of ribosome anti-association factor IF6. Nat Struct Biol 7, 1156-1164 (2000).

31. Klinge, S., Voigts-Hoffmann, F., Leibundgut, M., Arpagaus, S. \& Ban, N. Crystal structure of the eukaryotic $60 \mathrm{~S}$ ribosomal subunit in complex with initiation factor 6. Science 334, 941-948 (2012).

32. Ban, N. et al. A new system for naming ribosomal proteins. Curr Opin Struct Biol 24, 165-169 (2014).

33. Yip, M.C.J. et al. Mechanism for recycling tRNAs on stalled ribosomes. Nat Struct Mol Biol 26, 343-349 (2019).

34. Beard, C., Hochedlinger, K., Plath, K., Wutz, A. \& Jaenisch, R. Efficient method to generate single-copy transgenic mice by site-specific integration in embryonic stem cells. Genesis 44, 23-28 (2006).

35. Urlinger, S. et al. Exploring the sequence space for tetracycline-dependent transcriptional activators: novel mutations yield expanded range and sensitivity. Proc Natl Acad Sci U S A 97, 7963-7968 (2000).

36. Martin, T.E. \& Hartwell, L.H. Resistance of active yeast ribosomes to dissociation by KCl. J Biol Chem 245, 1504-1506 (1970).

37. Lee, S. et al. Somatic uniparental disomy mitigates the most damaging EFL1 allele combination in Shwachman-Diamond syndrome. Blood (2021).

38. Pronk, C.J. et al. Elucidation of the phenotypic, functional, and molecular topography of a myeloerythroid progenitor cell hierarchy. Cell Stem Cell 1, 428-442 (2007). 
39. Chen, K. et al. Resolving the distinct stages in erythroid differentiation based on dynamic changes in membrane protein expression during erythropoiesis. Proc Natl Acad Sci U S A 106, 17413-17418 (2009).

40. McGrath, K.E., Catherman, S.C. \& Palis, J. Delineating stages of erythropoiesis using imaging flow cytometry. Methods 112, 68-74 (2017).

41. Konstantinidis, D.G. et al. Signaling and cytoskeletal requirements in erythroblast enucleation. Blood 119, 6118-6127 (2012).

42. Jarzebowski, L. et al. Mouse adult hematopoietic stem cells actively synthesize ribosomal RNA. RNA 24, 1803-1812 (2018).

43. Gandin, V. et al. Eukaryotic initiation factor 6 is rate-limiting in translation, growth and transformation. Nature 455, 684-688 (2008).

44. Zhang, S., Shi, M., Hui, C.C. \& Rommens, J.M. Loss of the mouse ortholog of the shwachman-diamond syndrome gene (Sbds) results in early embryonic lethality. Mol Cell Biol 26, 6656-6663 (2006).

45. Tourlakis, M.E. et al. Deficiency of Sbds in the mouse pancreas leads to features of Shwachman-Diamond syndrome, with loss of zymogen granules. Gastroenterology 143, 481-492 (2012).

46. Shuga, J., Zhang, J., Samson, L.D., Lodish, H.F. \& Griffith, L.G. In vitro erythropoiesis from bone marrow-derived progenitors provides a physiological assay for toxic and mutagenic compounds. Proc Natl Acad Sci U S A 104, 8737-8742 (2007).

47. Signer, R.A., Magee, J.A., Salic, A. \& Morrison, S.J. Haematopoietic stem cells require a highly regulated protein synthesis rate. Nature 509, 49-54 (2014).

48. Scheres, S.H. \& Chen, S. Prevention of overfitting in cryo-EM structure determination. Nat Methods 9, 853-854 (2012).

49. Scheres, S.H. RELION: implementation of a Bayesian approach to cryo-EM structure determination. J Struct Biol 180, 519-530 (2012).

50. Kimanius, D., Forsberg, B.O., Scheres, S.H. \& Lindahl, E. Accelerated cryoEM structure determination with parallelisation using GPUs in RELION-2. Elife 5 (2016).

51. Zheng, S.Q. et al. MotionCor2: anisotropic correction of beam-induced motion for improved cryo-electron microscopy. Nat Methods 14, 331-332 (2017).

52. Rohou, A. \& Grigorieff, N. CTFFIND4: Fast and accurate defocus estimation from electron micrographs. J Struct Biol 192, 216-221 (2015).

53. Tan, S.J., Amos, W. \& Laughlin, S.B. Captivity selects for smaller eyes. Current Biology 15, R540-R542 (2005). 


\section{A Figure 1}

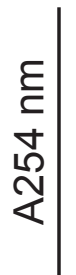
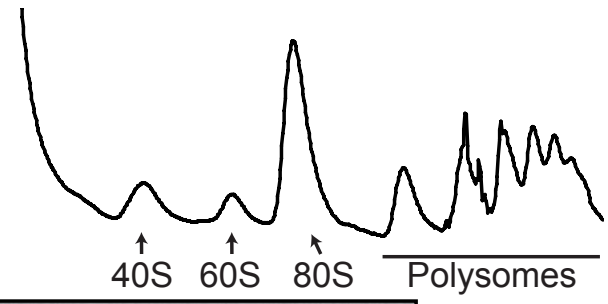

elF6

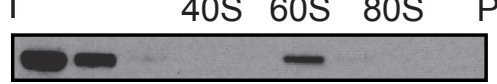

Rpl11 Rps19

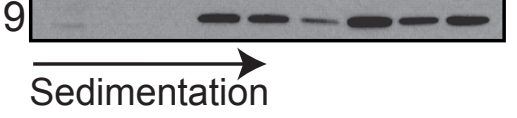

C

D
B

Cytoplasmic 60S subunit
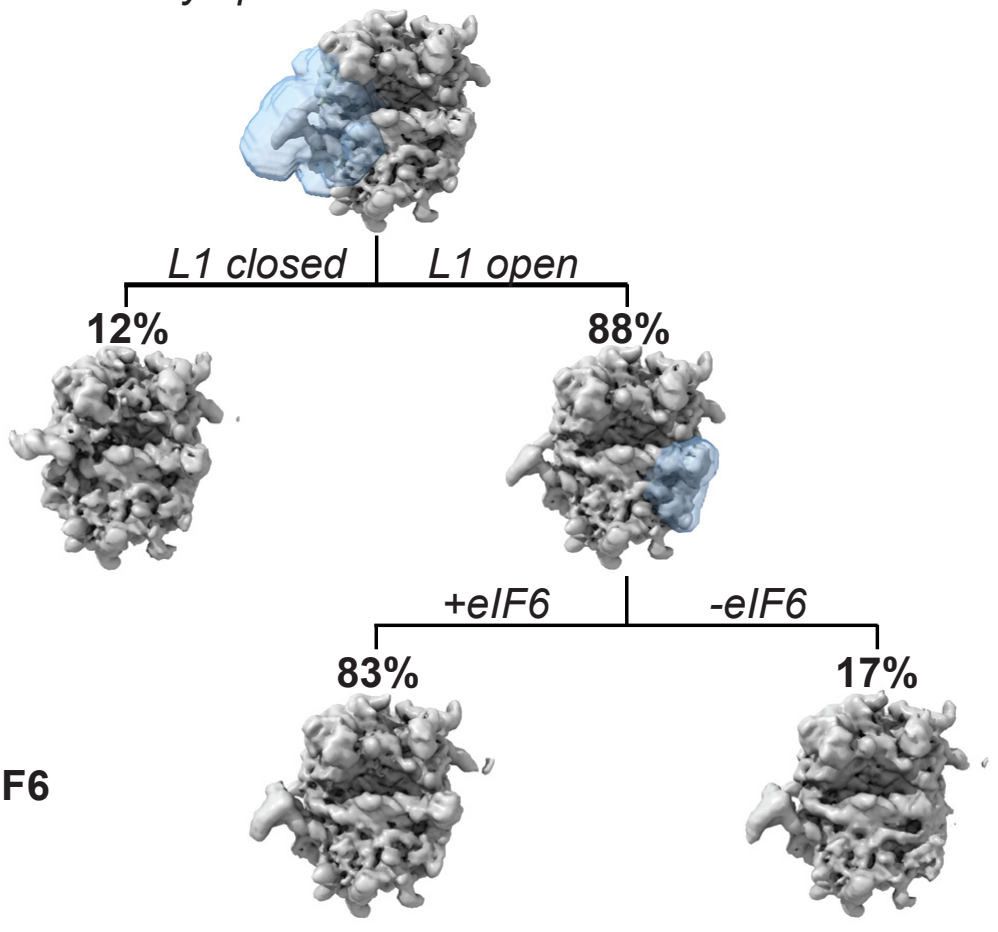
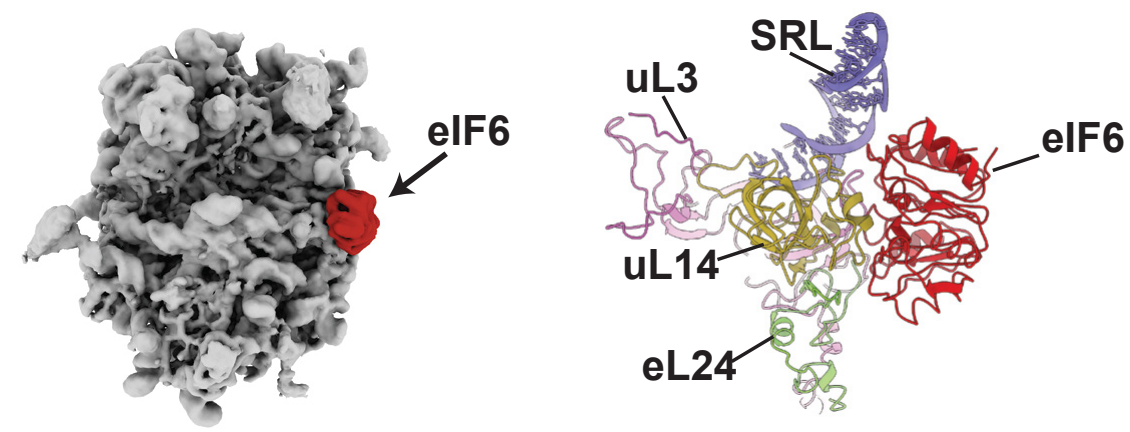
A Figure 3
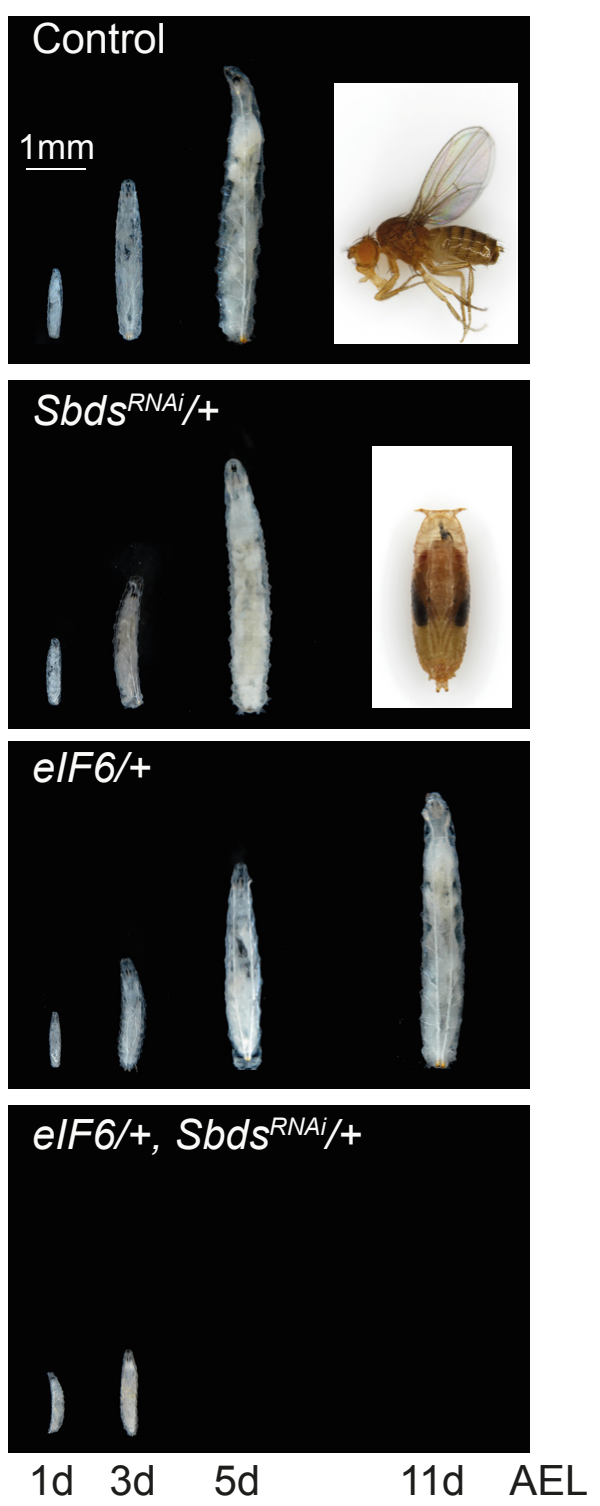

B

GMR-GAL4 >

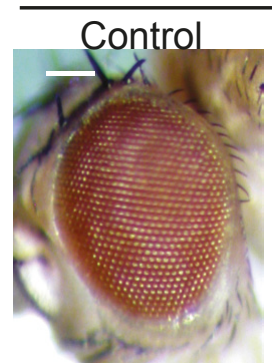

Sbds ${ }^{R N A i} /+$
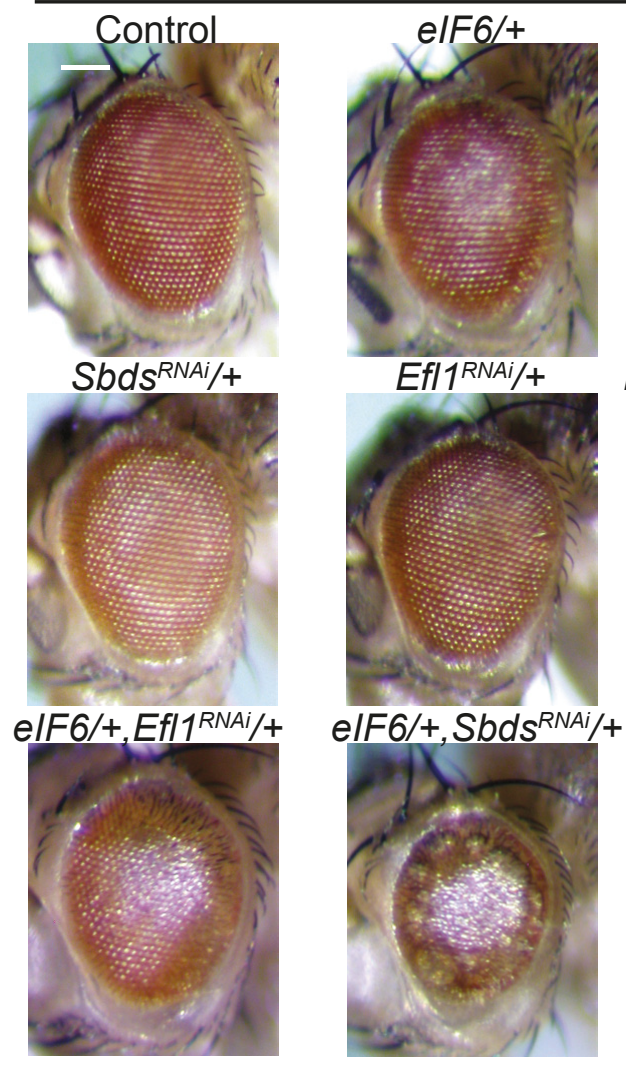

Efl $11^{\text {RNAi } /+}$

Efl $11^{R N A i} /+, S b d s^{R N A i} /+$

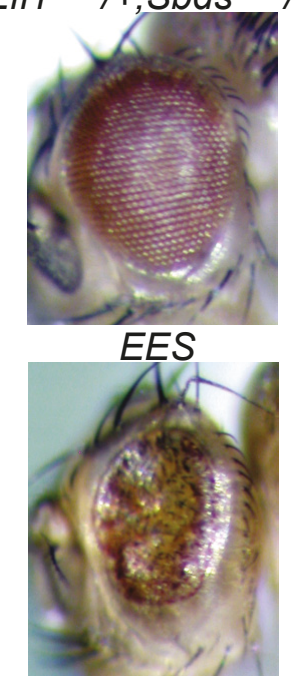

C En>GFP
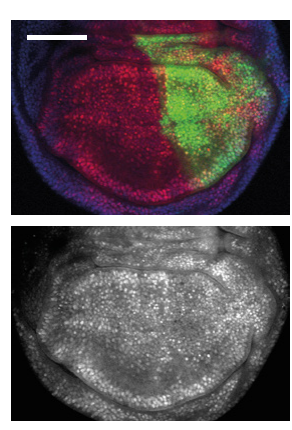

En>GFP, elF6/+
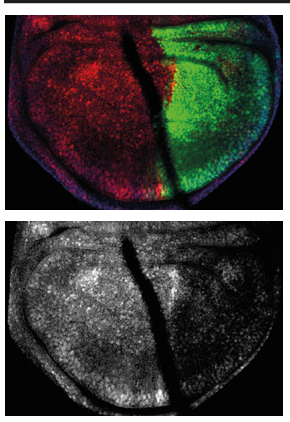

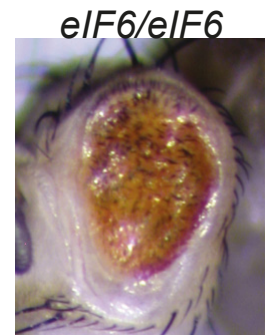

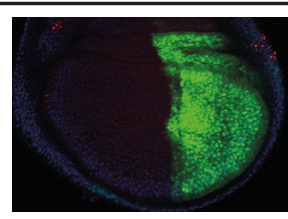

En $>$ GFP OP-Puro DAPI

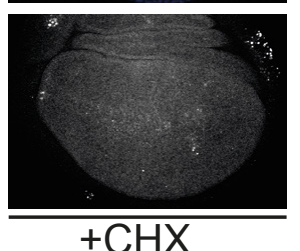

OP-Puro DAPI

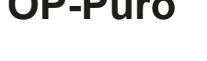




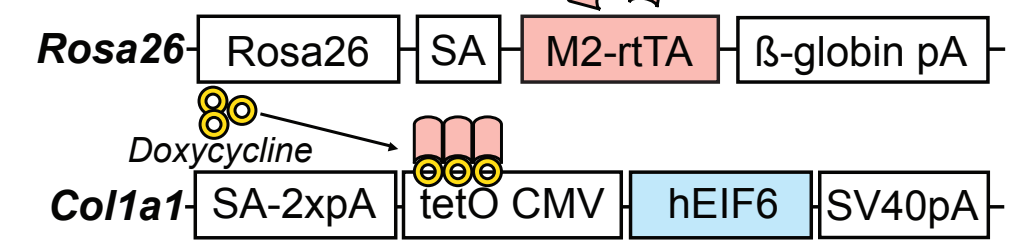

C

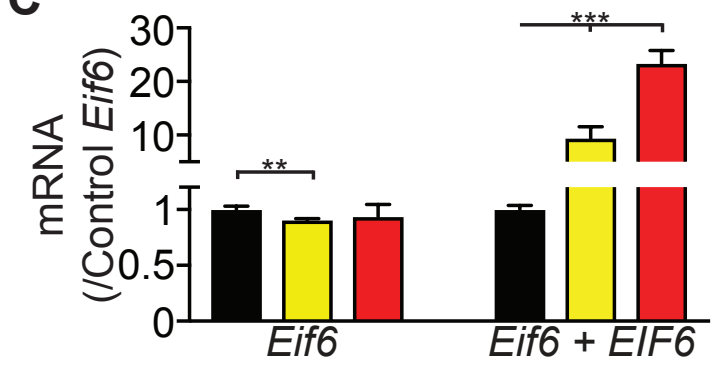

(Endogenous) (Total)

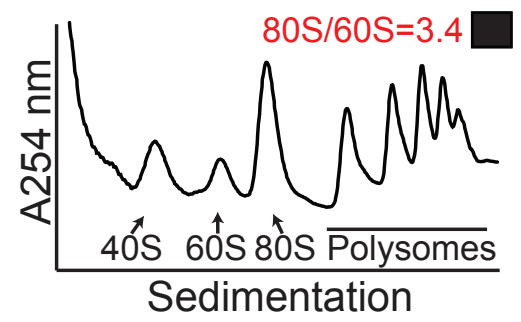

$\mathbf{F}$

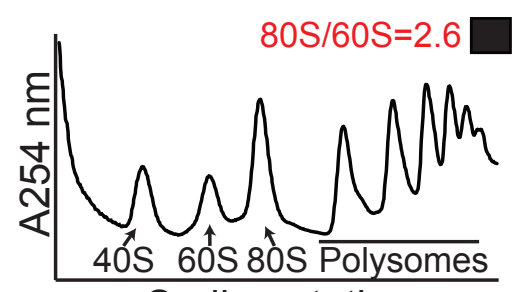

Sedimentation
G
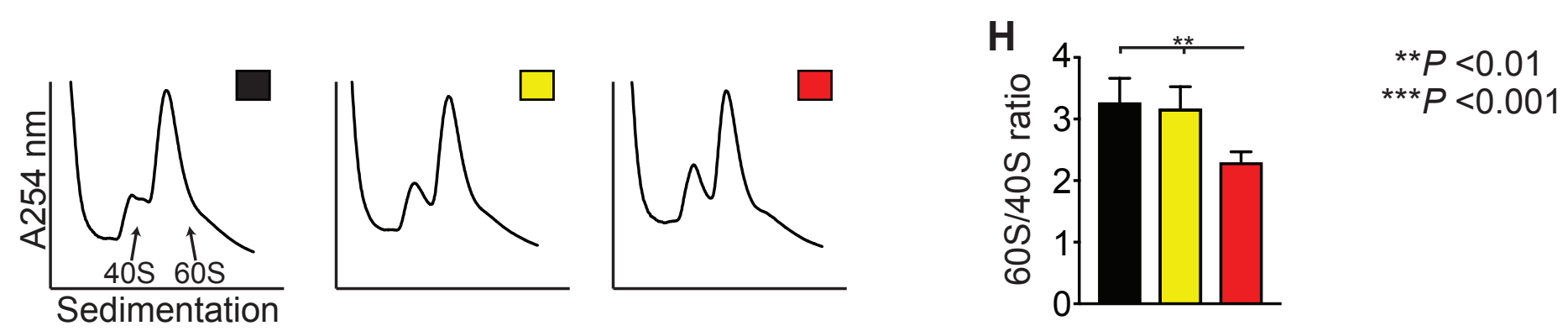
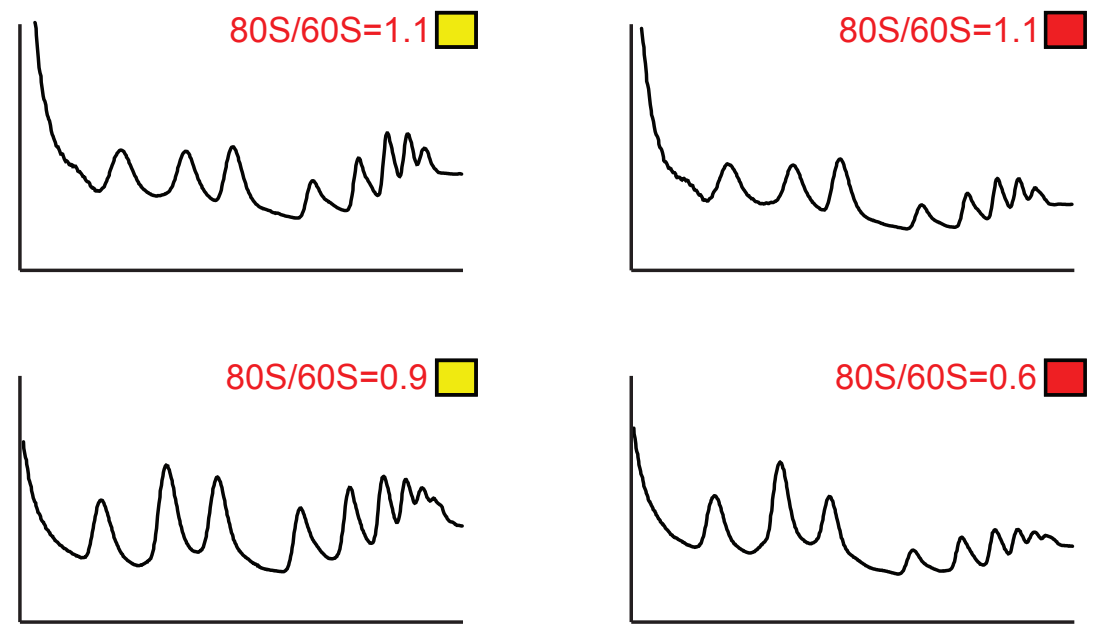

$\mathrm{H}$

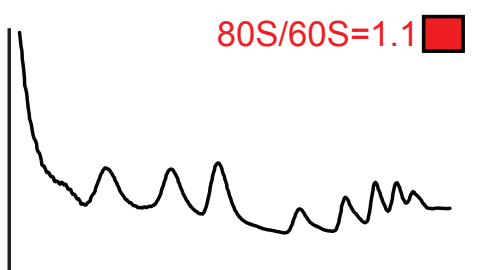

$80 S / 60 S=0.6$

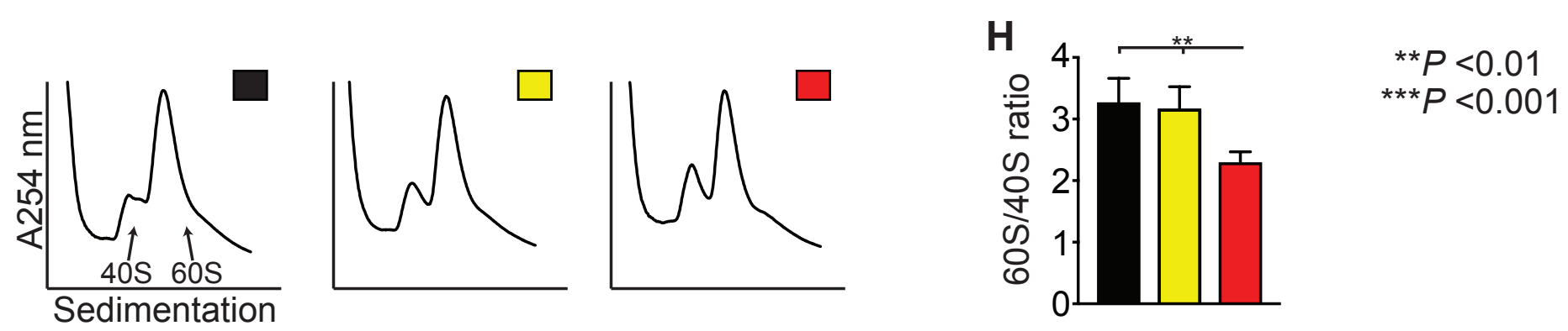

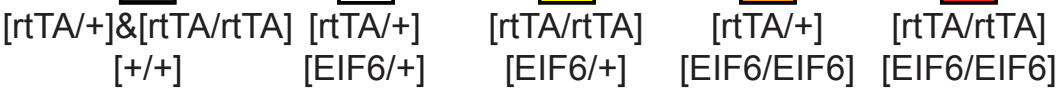

"Control" "elF6"
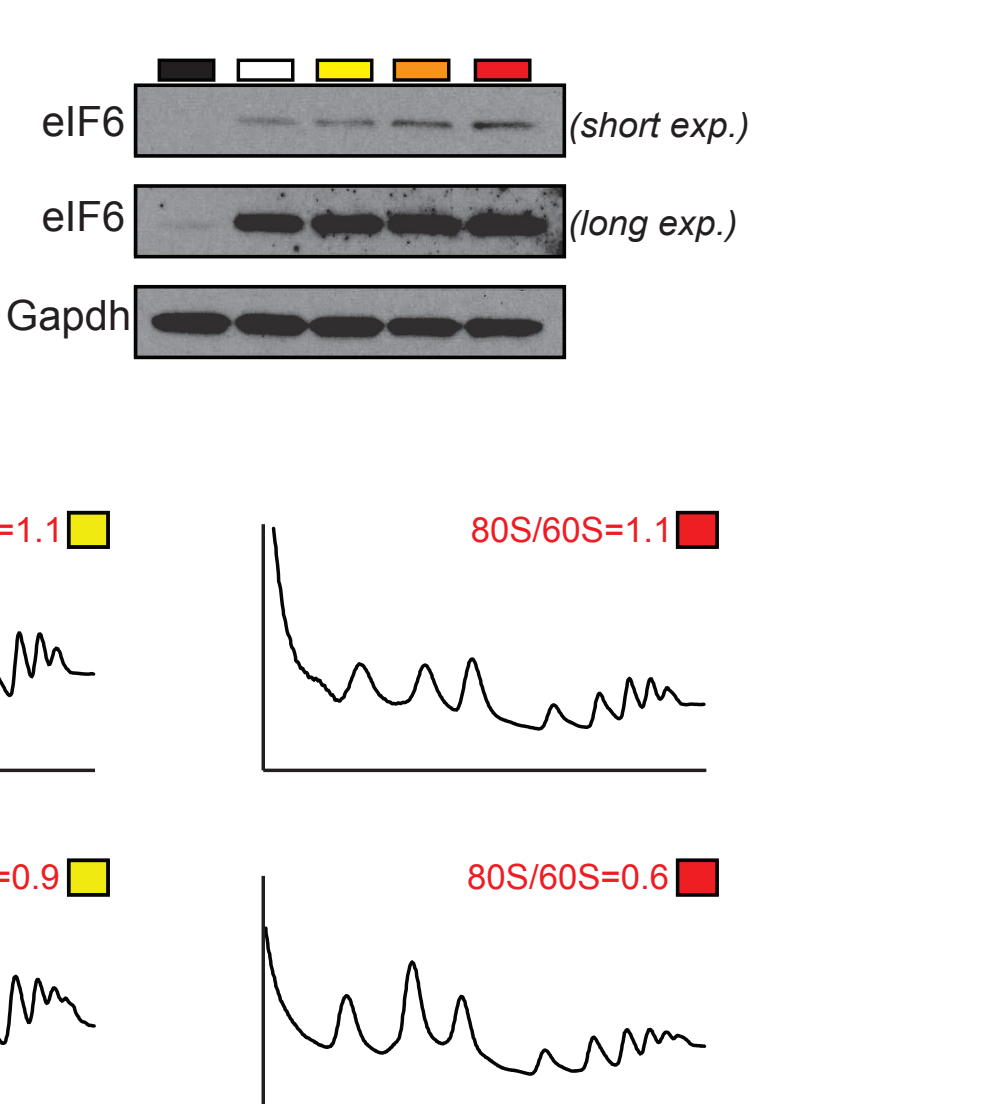

D

E 


\section{NUCLEUS}

CYTOPLASM

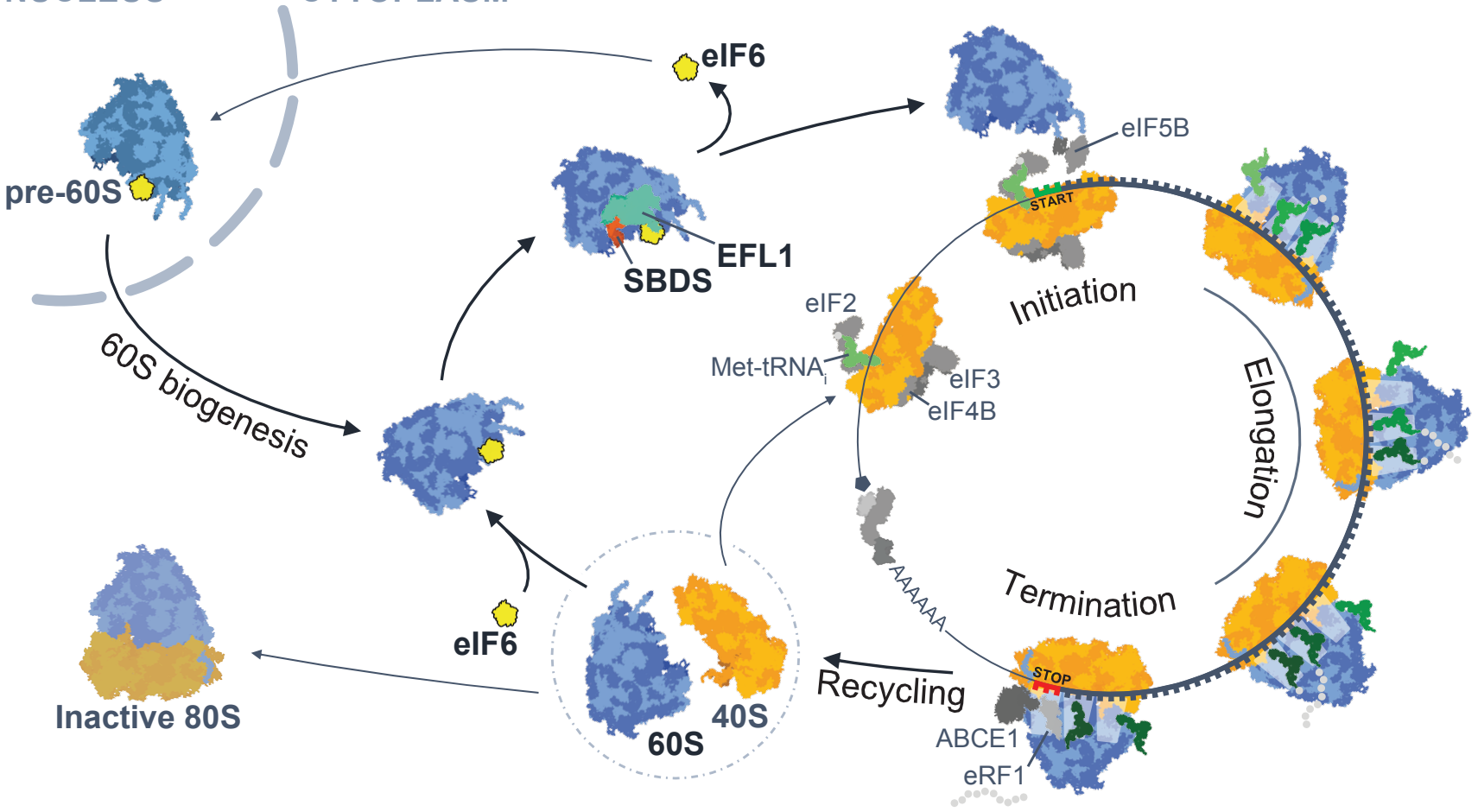


Supplementary Figure 1

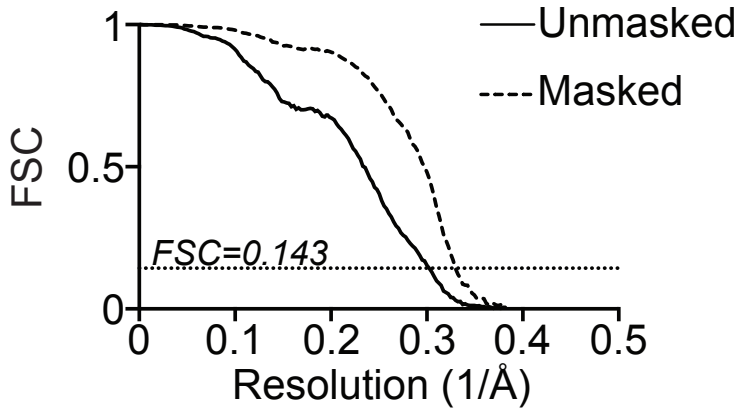


Supplementary Figure 2

elF6/+

elF6/+

Sbds RNAi/+ $^{\text {. }}$

Sbds $s^{R N A i} / S b d s$

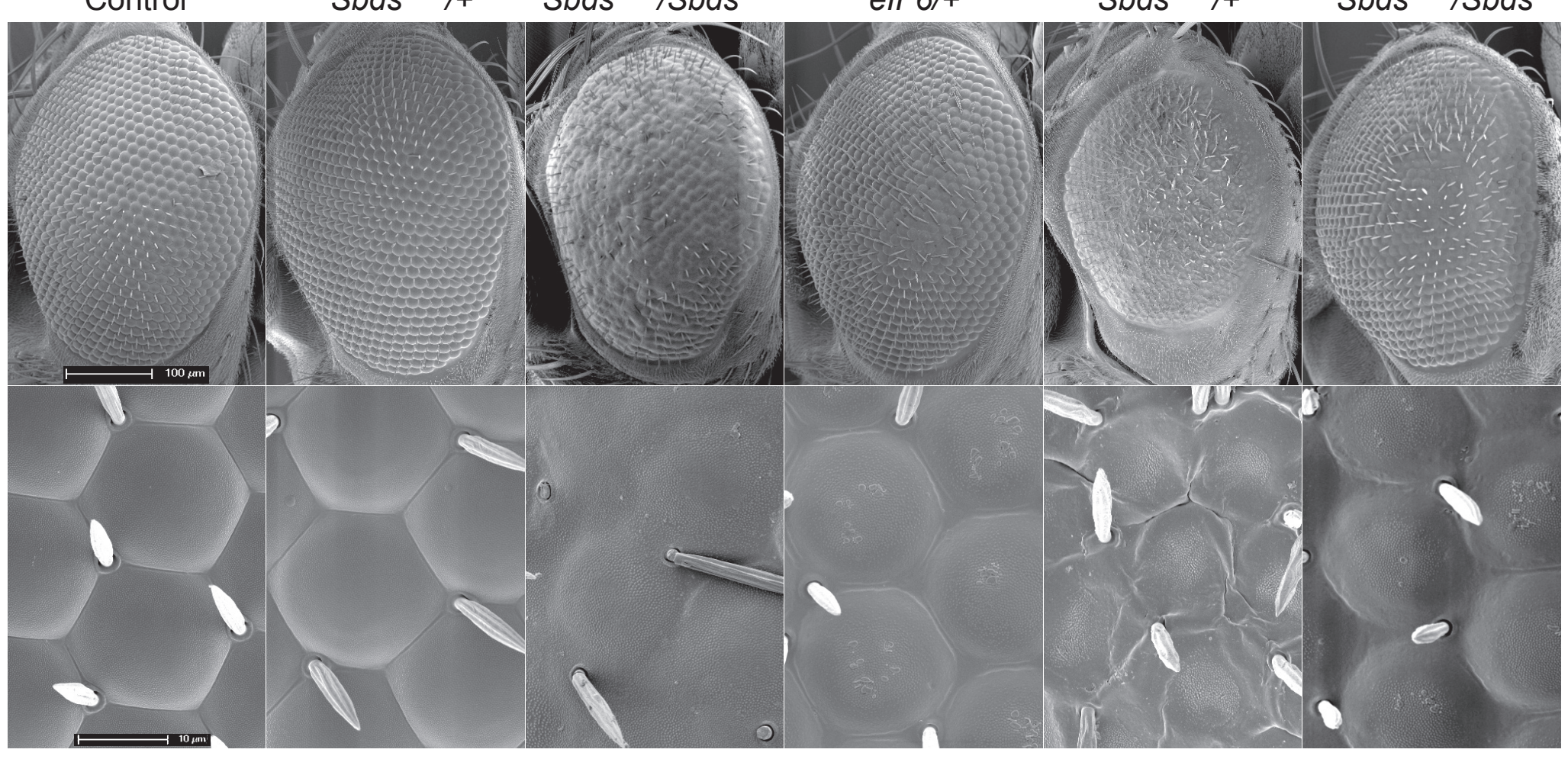


Supplementary Figure 3

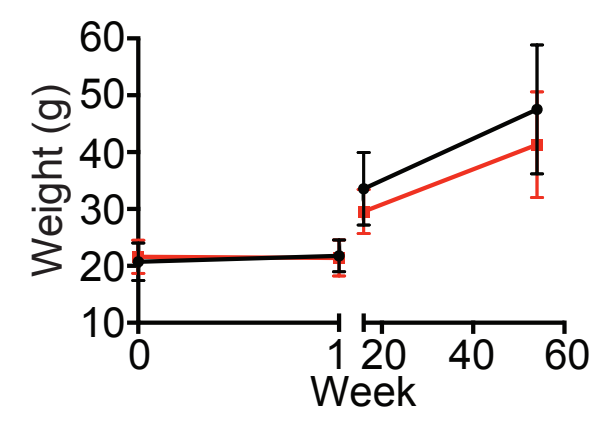

$\rightarrow$ Control

- elF6 ${ }^{\text {hi }}$ 
Supplementary Figure 5
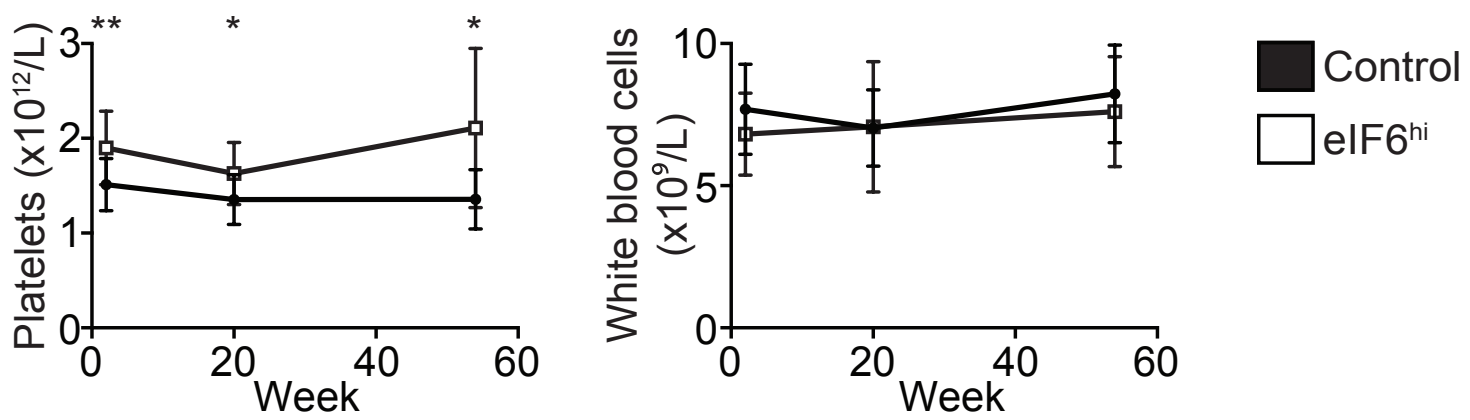
A Bone marrow

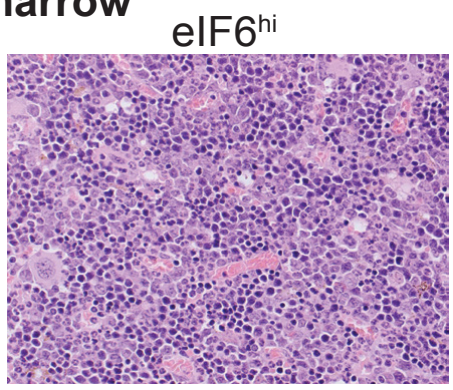

B

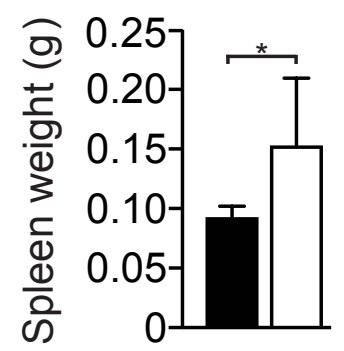

$\square$ Control $\square$ elF6 $^{\text {hi }}$
C

Control Spleen

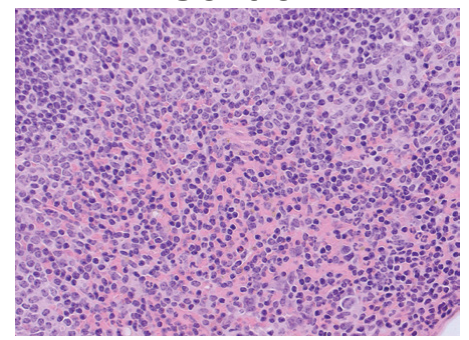

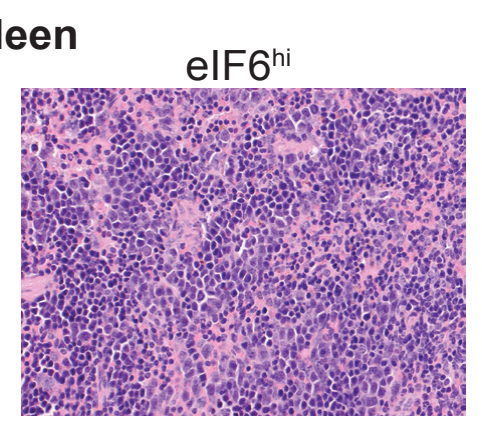

$$
\text { elF6 }^{\text {hi }}
$$


Supplementary Figure 7

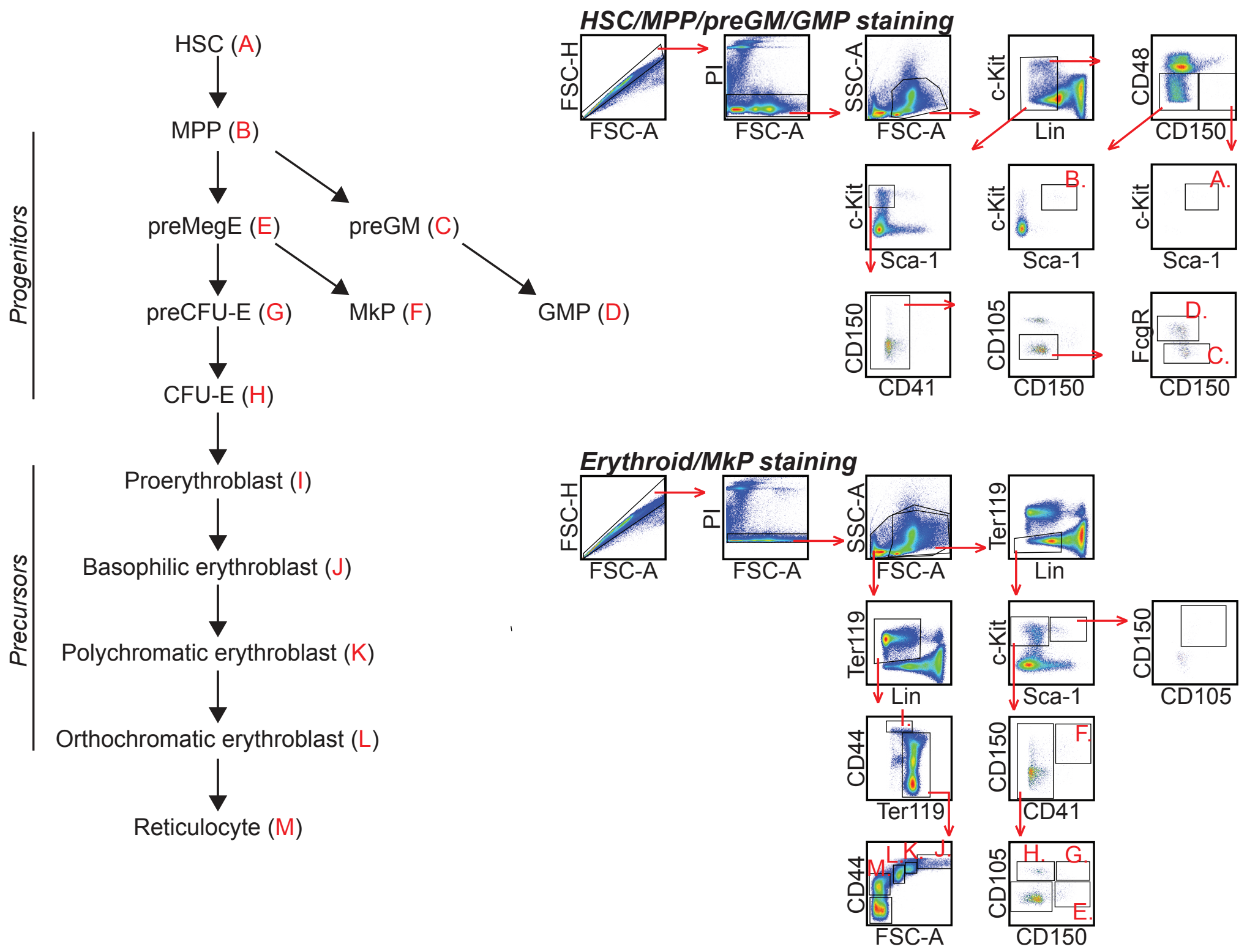


Supplementary Figure 10

A

Transplantation

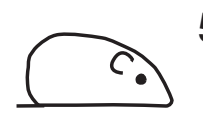

Control

elF6 ${ }^{\text {hi }}$
$5 \times 10^{6}$ BM cells (CD45.2)

Irradiated WT recipients

(CD45.1; 2x500 cGy)

B
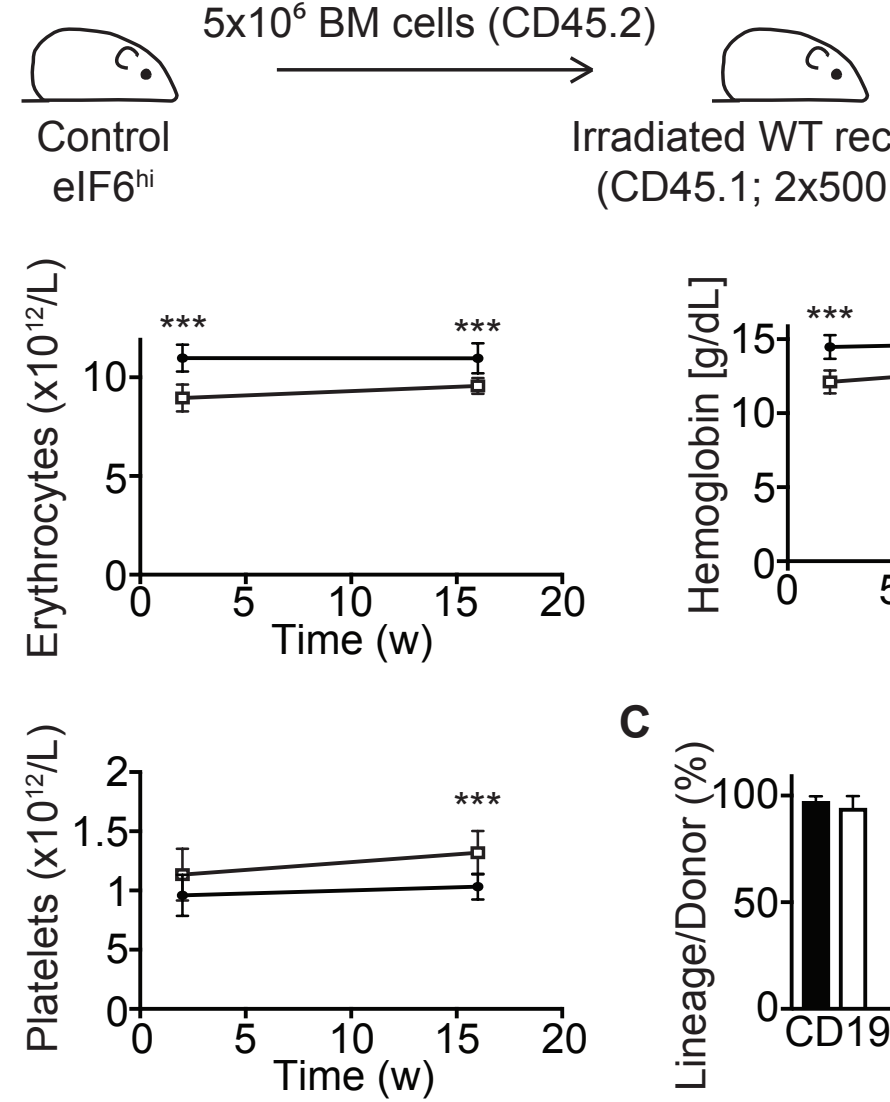

C
Doxycycline food

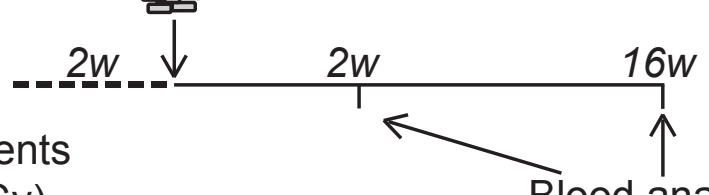

Blood analysis

(B-C)
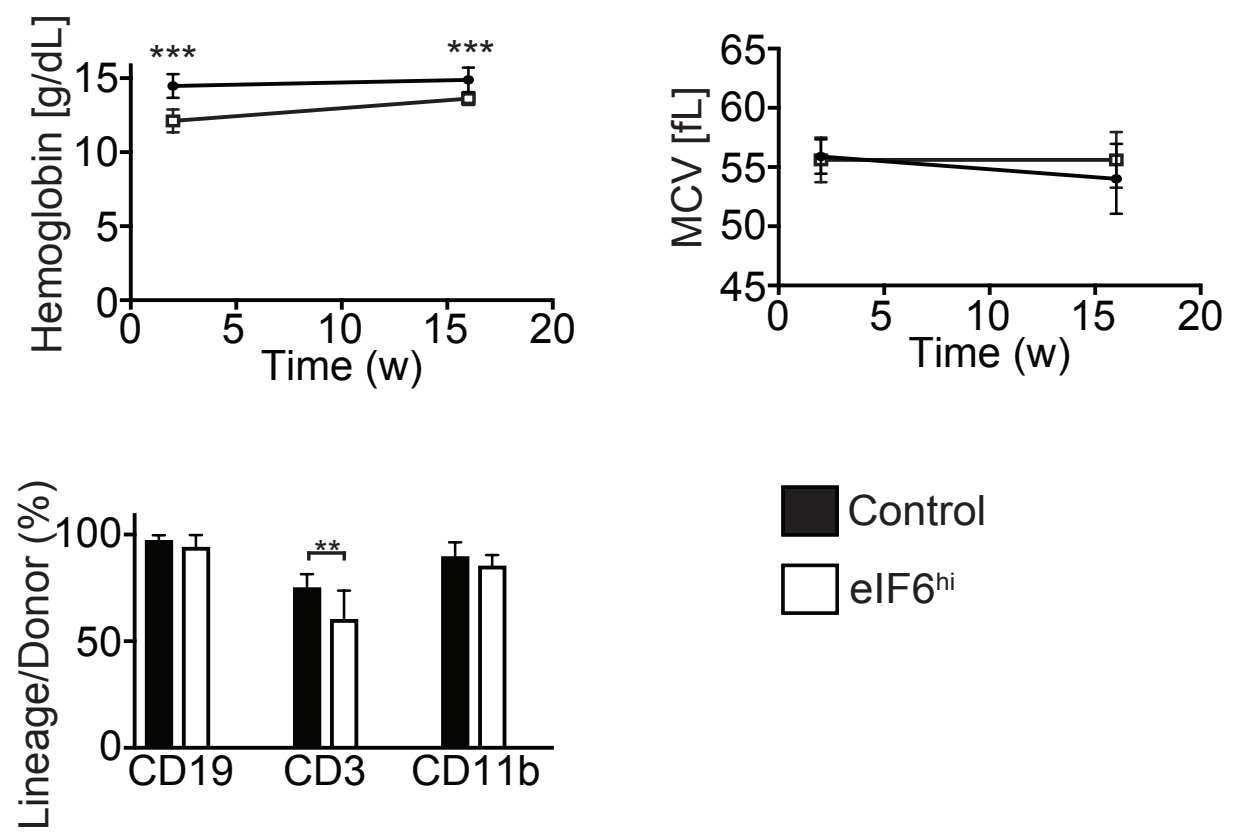

$\square$ Control $\square$ elF6 $^{\text {hi }}$ 